\section{Office of}

ENERGY EFFICIENCY \& RENEWABLE ENERGY

\section{OLED Lighting in the Offices of DeJoy, Knauf $\&$ Blood, LLP}

Prepared for the U.S. Department of Energy

Solid-State Lighting Program

July 2017

Prepared by Pacific Northwest National Laboratory

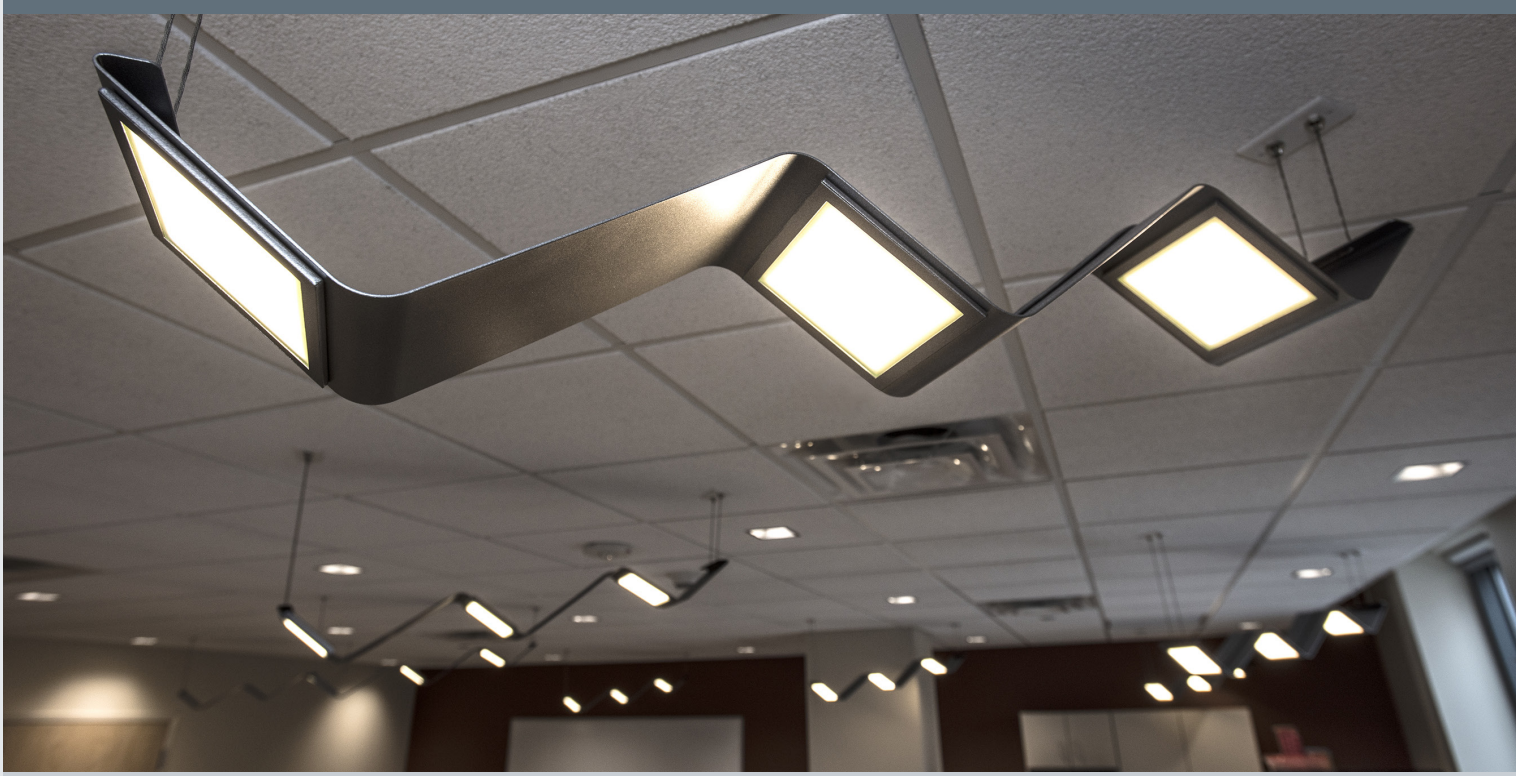




\title{
DISCLAIMER
}

This report was prepared as an account of work sponsored by an agency of the United States Government. Neither the United States Government nor any agency thereof, nor Battelle Memorial Institute, nor any of their employees, makes any warranty, express or implied, or assumes any legal liability or responsibility for the accuracy, completeness, or usefulness of any information, apparatus, product, or process disclosed, or represents that its use would not infringe privately owned rights. Reference herein to any specific commercial product, process, or service by trade name, trademark, manufacturer, or otherwise does not necessarily constitute or imply its endorsement, recommendation, or favoring by the United States Government or any agency thereof, or Battelle Memorial Institute. The views and opinions of authors expressed herein do not necessarily state or reflect those of the United States Government or any agency thereof.

\author{
PACIFIC NORTHWEST NATIONAL LABORATORY \\ operated by \\ BATTELLE \\ for the \\ UNITED STATES DEPARTMENT OF ENERGY \\ under Contract DE-AC05-76RL01830 \\ Printed in the United States of America \\ Available to DOE and DOE contractors from the \\ Office of Scientific and Technical Information, \\ P.O. Box 62, Oak Ridge, TN 37831-0062; \\ ph: (865) 576-8401 \\ fax: (865) 576-5728 \\ email: reports@adonis.osti.gov \\ Available to the public from the National Technical Information Service \\ 5301 Shawnee Rd., Alexandria, VA 22312 \\ ph: (800) 553-NTIS (6847) \\ email: orders@ntis.gov <http://www.ntis.gov/about/form.aspx> \\ Online ordering: http://www.ntis.gov
}




\section{OLED Lighting in the Offices of DeJoy, Knauf \& Blood, LLP}

Final report prepared in support of the U.S. DOE Solid-State Lighting Technology GATEWAY Program

Study Participants:

Pacific Northwest National Laboratory

DeJoy, Knauf \& Blood, LLP, Certified Public Accountants, Rochester NY

Naomi J. Miller

July 2017

Prepared for

the U.S. Department of Energy

under Contract DE-AC05-76RL01830

Pacific Northwest National Laboratory 


\section{Preface}

The U.S. Department of Energy's Solid-State Lighting program documents the performance of SSL products and systems based on standardized laboratory test results, additional specialized testing, mockup studies, and real-world field evaluations. This information is provided publicly for several purposes: 1) to track SSL technology performance improvement over time; 2) to identify technology challenges that impact performance and application of SSL; 3) to spur continued advancements in SSL technology, product design, and application; and 4) to maximize energy efficiency and decrease US energy use, while improving lighting quality. DOE does not endorse any commercial product or in any way provide assurance that other users will achieve similar results through use of these products. SSL technology continues to evolve quickly, so evaluation results should always be understood in the context of the timeframe in which products were acquired, tested, installed, and operated. Especially given the rapid development cycle for SSL products, specifiers and purchasers should always seek current information from manufacturers when evaluating such products. The two programs primarily involved in product evaluations are CALiPER and GATEWAY.

\section{CALIPER}

When CALiPER was launched its role was largely to test products and compare actual performance to manufacturer claims and to benchmark technologies. Early CALiPER testing also contributed fundamentally to the development of standardized photometric test methods specifically for SSL and the associated accreditation of testing laboratories. As the SSL market has matured, CALiPER has transitioned its evaluations to new products and functions, such as OLED based luminaires and color tunable products, as well as long-term product performance. CALiPER continues to support the development of new test procedures and application guidance, with DOE investigations providing data that is essential for understanding the most current issues facing the SSL industry. Data are gathered primarily through laboratory testing and mock-up installations.

\section{GATEWAY}

GATEWAY conducts field evaluations of high-performance SSL products to collect empirical data and document experience with field installations. GATEWAY provides independent, third-party data for use in decision-making by lighting manufacturers, users, and other professionals. Real-world installations often reveal product limitations and application issues that are not apparent from laboratory testing. GATEWAY typically documents pre- and post-installation light levels, color characteristics, energy intensity, and other performance attributes, and addresses application and maintenance of SSL products. In some cases, GATEWAY returns to projects after months or years of operation to take additional site measurements or remove luminaires and send to accredited laboratories for testing. While not possible for every project, such follow-up measurements have yielded useful data on dirt depreciation, color shift, luminous intensity distribution changes, and lumen depreciation over time.

For more information on the DOE SSL program, please visit http://www.ssl.energy.gov. 


\section{Acknowledgements}

This GATEWAY report documents OLED luminaires installed in an accounting firm's offices in Rochester, NY. The cooperation and input of the principals and members of the firm have been invaluable, and the sharing of their workspace photographs made this process easier and the report more visually appealing. GATEWAY would also like to acknowledge input from the luminaire manufacturers, Acuity Brands Winona ${ }^{\circledR}$ Lighting, Designplan, Visa Lighting, OLEDWorks LLC, Birot, OMLED, V2 Lighting Group, Inc., OLED Devices LLC, Acuity Brands Mark Lighting, and Acuity Brands Gotham Lighting, who generously provided photos, drawings, photometry, and technical information for the report. NYSERDA provided funding for OLEDWorks LLC to purchase and demonstrate OLED luminaires at the DeJoy, Knauf \& Blood, LLP offices. OLEDWorks LLC assisted DeJoy, Knauf \& Blood, LLP by working with their luminaire customers to procure many of the OLED luminaires installed on the project. Point Source Group, Inc. in Rochester provided much of the lighting and controls design. SEI Design Group, Inc. provided comprehensive interior design and space planning consulting services. 


\section{Executive Summary}

The U.S. Department of Energy (DOE) has supported solid-state lighting (SSL) in the United States for over 13 years, through research and development (R\&D) funding that has led to technology breakthroughs, development of intellectual property, and streamlined product manufacturing. OLEDWorks LLC, Inc. is one of the recipients of R\&D funding for developing organic light-emitting diode (OLED) materials and manufacturing methods, and is the only US based OLED manufacturer. David DeJoy is a co-founder and CEO of OLEDWorks LLC, and also a founding partner in the accounting firm of DeJoy, Knauf \& Blood, LLP (DKB) in Rochester NY. On behalf of OLEDWorks and DKB, DeJoy invited DOE to evaluate the new lighting system planned for the DKB offices as a GATEWAY evaluation.

DeJoy, Knauf \& Blood, LLP is an accounting and business advisory firm with its headquarters in Rochester N.Y. that provides services to companies in the high-tech industry and a wide variety of other industries. DeJoy, Knauf \& Blood, LLP's team approach to providing professional services has resulted in their reputation as TeamDKB. TeamDKB's new office is located at Tower280 at Midtown in the heart of Downtown Rochester, after having moved from a 1980's-vintage downtown office that they had leased for 25 years.

TeamDKB committed to an unconventional office organization philosophy, where there are few private offices, and those offices use glass walls to encourage transparency and the sharing of daylight. Most of the office space is open plan, with work stations aligned along a structural spine. Spines are arranged in rows, which enables teams of employees to work closely together in groups. These teams come together for a specific project, spanning a period of days, weeks, or months, and then when a project ends, the employees recoalesce in different locations for the next project with different staff as needed. Workstations are thus temporary and identically equipped with monitors and computer connections, and the employee rolls a small cabinet of work and personal belongings to the new workstation.

Because TeamDKB provides tax and business advisory services for OLEDWorks LLC, and one of the partners in TeamDKB has an interest in OLEDWorks LLC, the company wanted to explore SSL (both LED and OLED products) in their new office spaces. Although LED products are well established in the marketplace, OLED products are still relatively untested. The large number of different OLED panel luminaires used in these offices, including some from Mexico and Europe, makes the installation unique, and therefore worth studying. OLED luminaires are primarily located in visually prominent areas: conference rooms, partner offices (Figure ES.1), the break room and lounge table areas, entry corridors and reception desk. An amber OLED marker light is used in the Zen/Mother's room, a few angled OLED task lights add soft localized desk lighting in private offices, and a couple of pendant lights add a decorative touch to the copy room. All of the luminaires use OLEDWorks LLC OLED panels; almost all the OLED luminaires are connected to 0-10V dimmers. 
The offices are a demonstration site for commercial OLED luminaires, but are fully functional and used by the staff. LED luminaires do most of the lighting work in the open office space and private offices, and consist of recessed linear 2-inch-wide slots, pendant-mounted direct/indirect linear 2-inchwide pendants, and recessed downlights. Floor-to-ceiling windows provide plentiful daylight, except on short winter days. Anonymized feedback from employees about this new office space has been very positive, especially given the contrast to their previous rabbit-warren office layouts with dated, fixedoutput, T8 fluorescent, deep-cell parabolic louver luminaires. They appreciate the soft, comfortable appearance of the OLED lighting and enjoy showing a new kind of SSL to visitors, and those who have explored the dimming options appreciate the flexibility. Employees also like the LED luminaires, although some find them excessively bright to view.

Efficacy performance of the OLED-only luminaires ranges from 21 to $58 \mathrm{~lm} / \mathrm{W}$, depending on the generation of OLEDWorks panels used in the luminaire, as well as the configuration of the luminaire and driver efficiency. Luminances of the exposed panels measured as high as $9318 \mathrm{~cd} / \mathrm{m}^{2}$, but it is common to find conference rooms where the OLED luminaires have been dimmed by employees to a level of 3300 to $6000 \mathrm{~cd} / \mathrm{m}^{2}$, and subsequent occupants use the dimmer/switch to turn the luminaires on or off, without touching the dimming setting. ${ }^{1}$

Temporal lighting artifact (TLA; aka flicker) measurements were taken of the LED and OLED luminaires in the DKB offices. Only one of the OLED products produced flicker or stroboscopic effects that would not meet the IEEE Standard P1789-2015 recommendations for reducing flicker, even when the luminaires were dimmed to their lowest settings. (Notably, many of the OLED drivers shifted the frequency to $1000 \mathrm{~Hz}$ or higher when dimmed to their lowest setting, making any increased modulation far less detectable.) Of the LED luminaires, only one pendant downlight produced noticeable stroboscopic effects, with a measured frequency of $120 \mathrm{~Hz}, 48 \%$ flicker, Flicker Index of 0.147 at full output.

${ }^{1}$ As a reference, surface luminances of T12 fluorescent lamps range from approximately 6000 - 8000 $\mathrm{cd} / \mathrm{m}^{2}$; T8 fluorescent lamps from $8000-11,000 \mathrm{~cd} / \mathrm{m}^{2}$; T5 fluorescent lamps from 16,000 - 35,000 cd/m² depending on output level and ballast factor. 


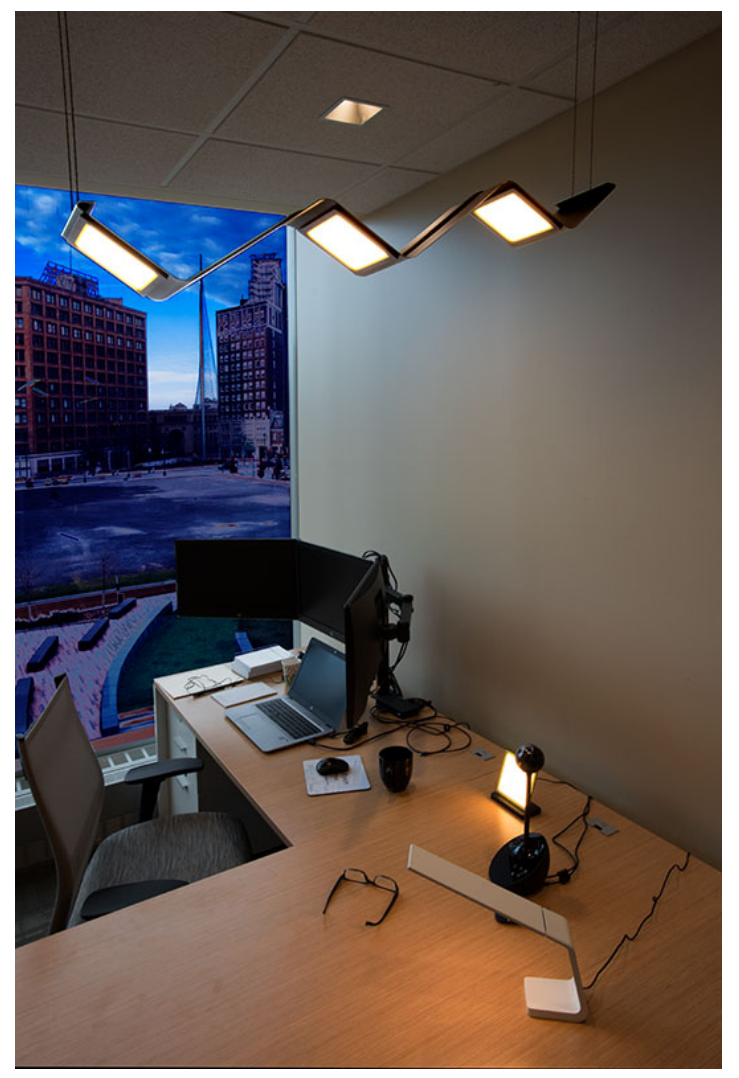

Figure ES.1. A perimeter office at TeamDKB, featuring an OLED pendant, an OLED task light (in white), and a single-panel OLED award with printed text and images backlit by a single OLED lighting panel. Photo courtesy OLEDWorks LLC and DeJoy Knauf \& Blood, LLP.

Field measurements of white OLED panel color in different luminaires yielded consistent correlated color temperature (CCT) values ranging from 2911 to $3074 \mathrm{~K}$, with color rendering index (CRI) values from 79 to 91. The total connected lighting load using the combination of OLED and LED luminaires was calculated at $0.6 \mathrm{~W} / \mathrm{ft}^{2}$, well below the ASHRAE/IES 90.1-2013 ${ }^{1}$ maximum allowed lighting power density (Building Area Method) of 0.82 for office spaces.

In most of the TeamDKB workspaces, OLED luminaires were installed in a supporting role with LED luminaires and good daylight design. LEDs and daylight provide the necessary illuminance levels for the primary work areas, while OLED products complement the visual environment with comfortable luminance levels, acceptable performance in terms of color quality, flicker, and controllability, and attractive design elements. In conference and break room spaces, OLED luminaires provide both the needed task lighting and the face and room surface lighting, while serving as the focal design element.

On-going concerns for OLED architectural lighting are a premium luminaire price point that limits its wider use in projects and applications, low efficacy compared to LED luminaires, and rising panel voltage and power draw over time. The OLED luminaires on this project range between 20 and $60 \mathrm{~lm} / \mathrm{W}$, compared to the LED products at approximately 80 to $90 \mathrm{~lm} / \mathrm{W}$. However, projected performance for the

\footnotetext{
${ }^{1}$ http://www.techstreet.com/ashrae/standards/ashrae-90-1-2013-i-p?utm_source=promotion\&utm_medium =landingpage\&utm_campaign=86273\&utm_term=86273\&utm_content=86273\&gateway_code=ashrae\&product_id $=1865966 \&$ ashrae_auth_token=
} 
next generation of OLED panels is 80 to $90 \mathrm{~lm} / \mathrm{W}$ at a nominal 8300 to $3000 \mathrm{~cd} / \mathrm{m}^{2}$, respectively; lifetime between 30,000 and 50,000 hours, respectively; and CRI of 90.

OLED panels draw more power as they age, so it is important for design professionals to provide "headroom" on the OLED loads in electrical circuits so that circuits will not be overloaded over time. An approximate additional $15 \%$ of power draw is also recommended in lighting power density calculations to account for panel-to-panel variations when new, panel changes over time, and for variations in ambient temperature. 


\section{Contents}

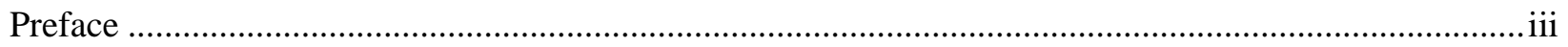

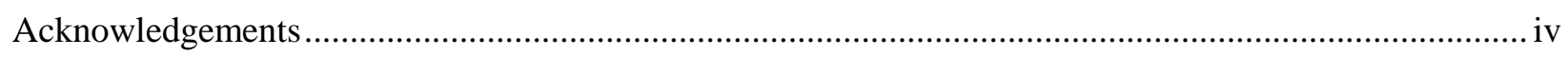

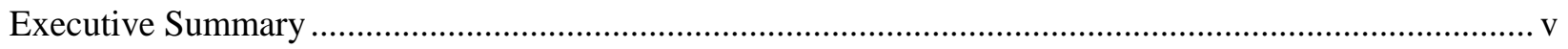

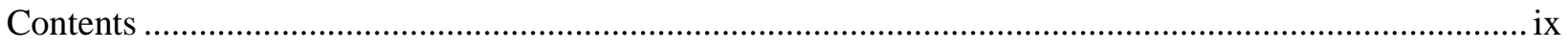

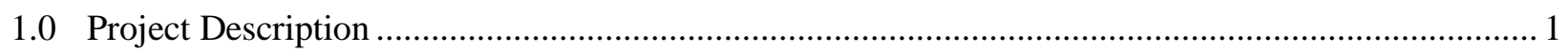

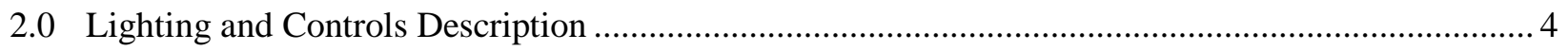

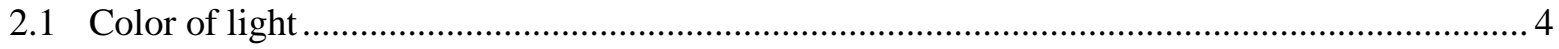

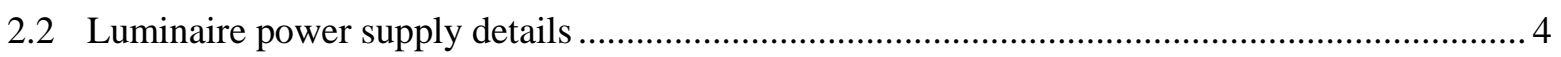

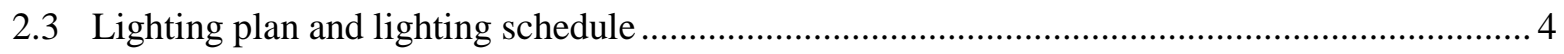

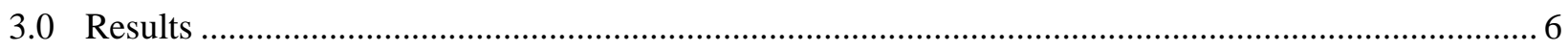

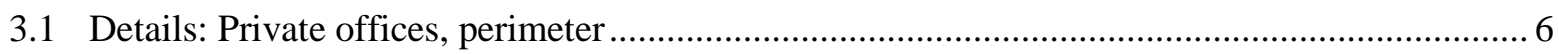

3.2 Details: Private offices, interior....................................................................................... 7

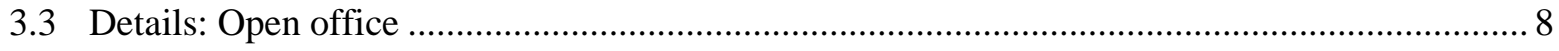

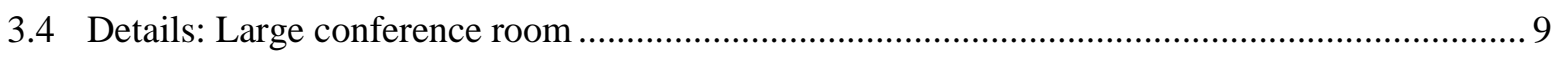

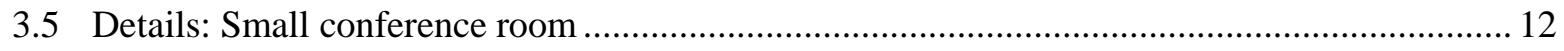

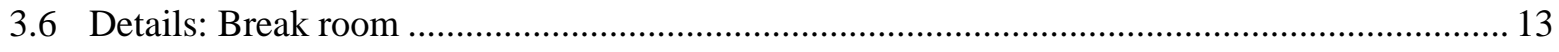

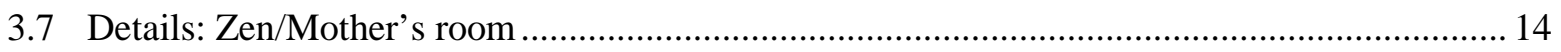

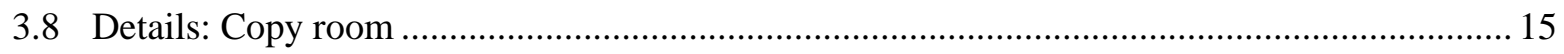

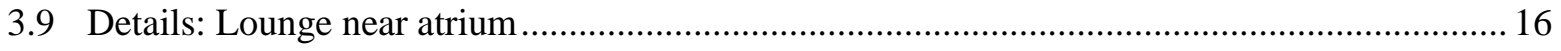

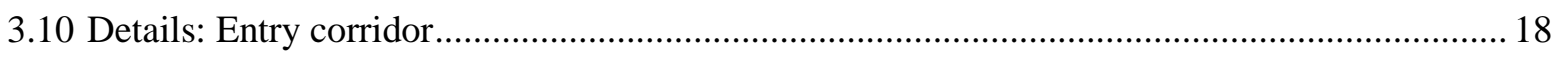

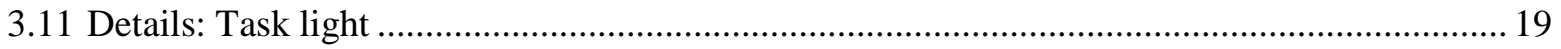

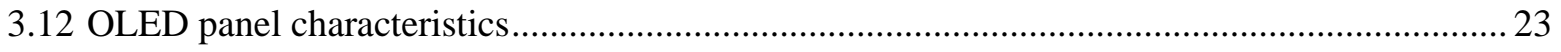

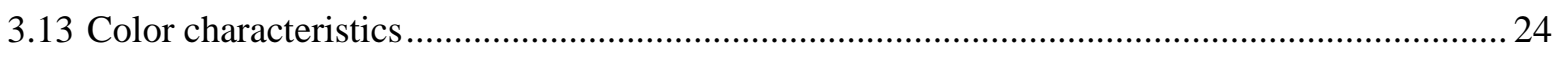

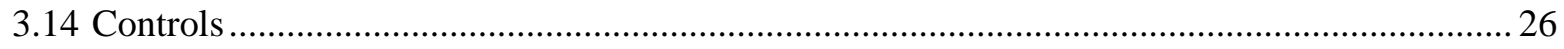

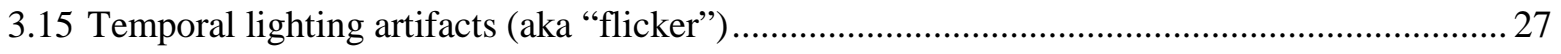

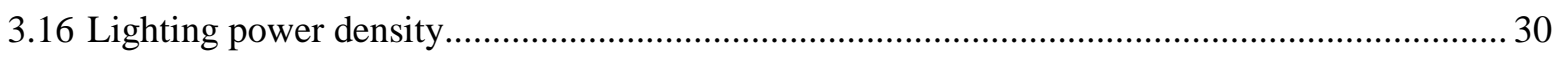

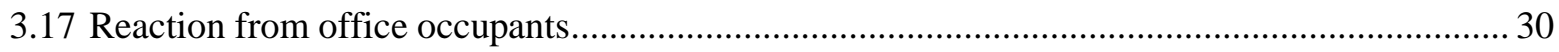

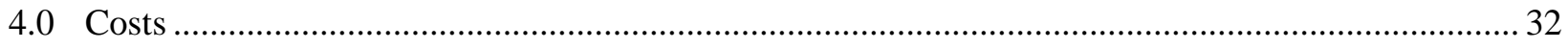

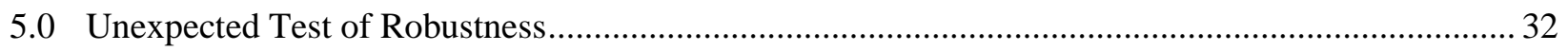

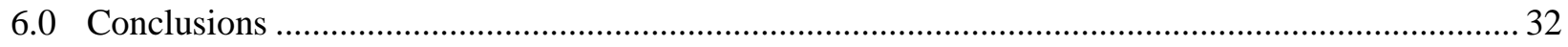

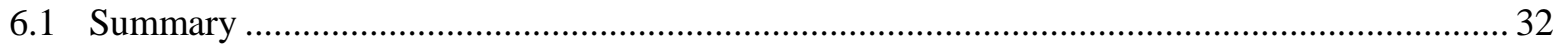

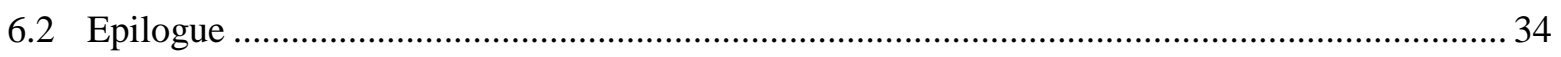

Appendix A TeamDKB Offices Lighting Power Density Calculation, Total Connected Lighting Load.. 35 Appendix B PNNL Interview Questions for TeamDKB staff, Before and After Move to New Offices... 37 


\subsection{Project Description}

DeJoy, Knauf \& Blood, LLP is an accounting and business advisory firm with its headquarters in downtown Rochester N.Y. The firm's services range from traditional audit and tax compliance and consultation to an extensive range of business advisory services. Also calling itself TeamDKB, the firm has about 60 employees. They moved in 2016 from 1980s-vintage downtown offices that they had leased for 25 years (Figure 1) to new tenant office spaces at 280 East Broad Street, in an area of Rochester experiencing a building and occupancy renaissance after decades of a depressed business climate. In this move, TeamDKB committed to an unconventional philosophy of office organization, where there are few private offices, and those offices feature two glass walls to encourage transparency and the sharing of daylight. Most of the office space is open plan, with work stations aligned along structural partition spines. The spine and workstation layout enables teams of employees to work closely together in teams. These teams come together for a specific project, spanning a period of days, weeks, or months, and then when a project ends, employees recoalesce in a different team and location for the next project.

Workstations are thus temporary and identically equipped with three display screens and computer connections. The employee rolls a small filing cabinet of personal belongings and work materials to the new workstation, and they are ready to go.

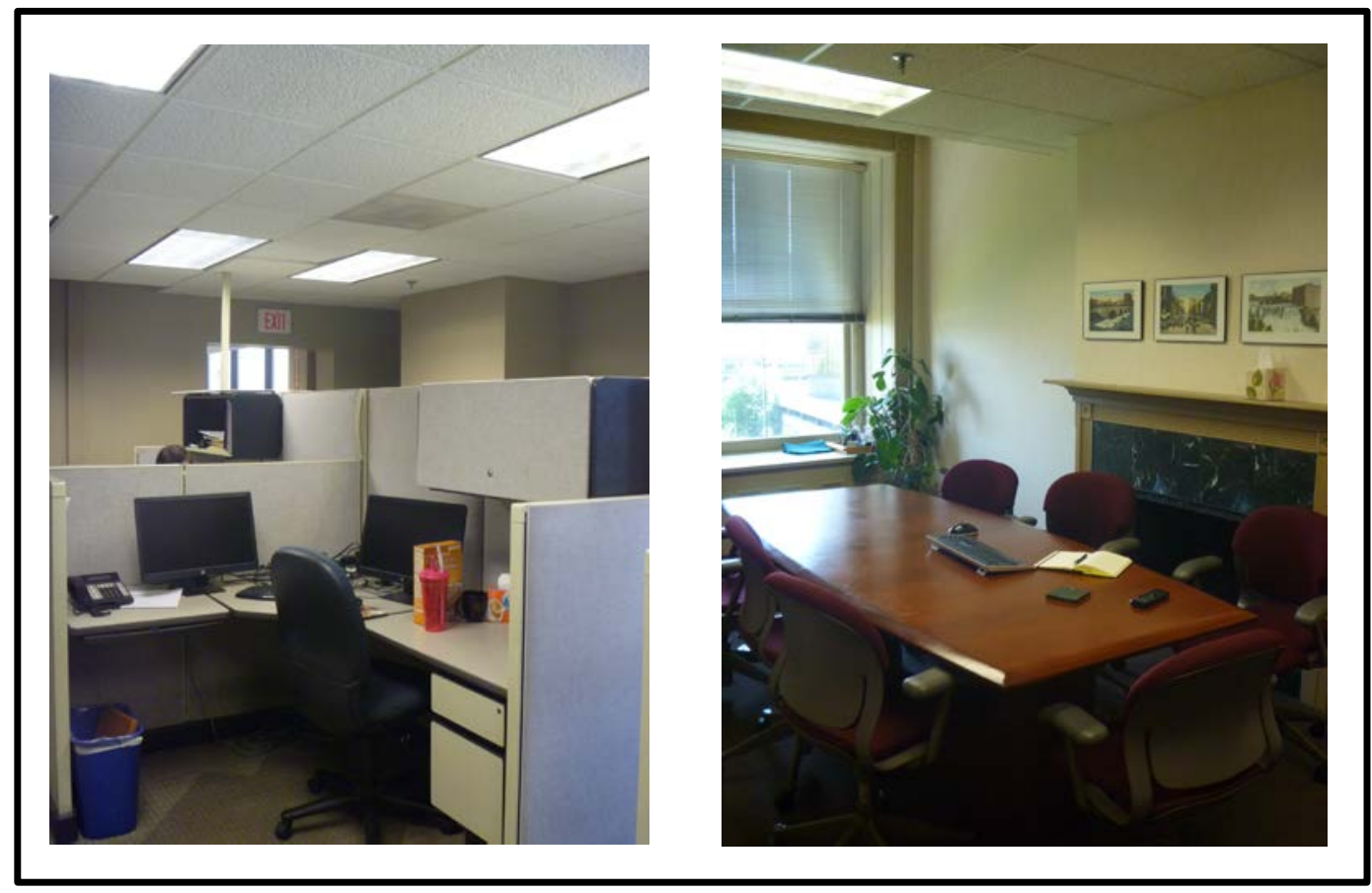

Figure 1. TeamDKB's previous offices in downtown Rochester. Open plan office (left); conference room (right). Lighting was recessed three-lamp fluorescent troffers with deep-cell parabolic louvers. Lamps were F28T8/741 fluorescent with correlated color temperature (CCT) of $3797 \mathrm{~K}$, color rendering index (CRI) of 81, and an R9 of 6. Photos: Pacific Northwest National Laboratory (PNNL). 
One of the founding partners of TeamDKB, David DeJoy, is also a founding partner and CEO of OLEDWorks LLC in Rochester NY, the only manufacturer of organic light-emitting diode (OLED) panels in the US. TeamDKB performs tax and business advisory services for OLEDWorks LLC and decided to experience solid-state lighting (SSL) in their new office spaces. The tenant-improvement build-out included both LED and OLED lighting products. Although LED luminaires are well established in the marketplace, OLED luminaires are still relatively untested ${ }^{3,4,5}$. The large number of different OLED luminaires used in these offices makes this installation unique, and therefore worth studying. OLEDWorks and TeamDKB invited DOE to evaluate the installation as a GATEWAY project.

To the greatest extent possible, PNNL implemented this GATEWAY evaluation in a way that produced objective results, uninfluenced by the business relationship between TeamDKB and OLEDWorks LLC. Nonetheless, one must interpret the subjective comments by TeamDKB employees on the final lighting installation carefully because it was not possible to conduct interviews in a way that would completely isolate any effects of that business relationship.

The new office space comprises 13,905 $\mathrm{ft}^{2}$. The space feels open, airy, and contemporary, with bright accent colors, playful non-orthogonal wall and furniture angles, and a combination of finished acoustical and exposed ductwork ceilings. (See floor plan, Figure 2.)

\footnotetext{
${ }^{3}$ An earlier DOE GATEWAY study on OLEDs can be found at https://energy.gov/sites/prod/files/2016/04/f30/2016_gateway_aurora-oled.pdf

${ }^{4}$ A CALiPER study on Photometric Testing, Laboratory Teardowns, and Accelerated Lifetime Testing of OLED Luminaires can be found at https://energy.gov/sites/prod/files/2016/10/f33/caliper-24_oled-luminaires.pdf

${ }^{5}$ The DOE issued a report in 2016 on OLED Lighting Products: Capabilities, Challenges, Potential. https://energy.gov/sites/prod/files/2016/08/f33/ssl_oled-products_2016.pdf
} 


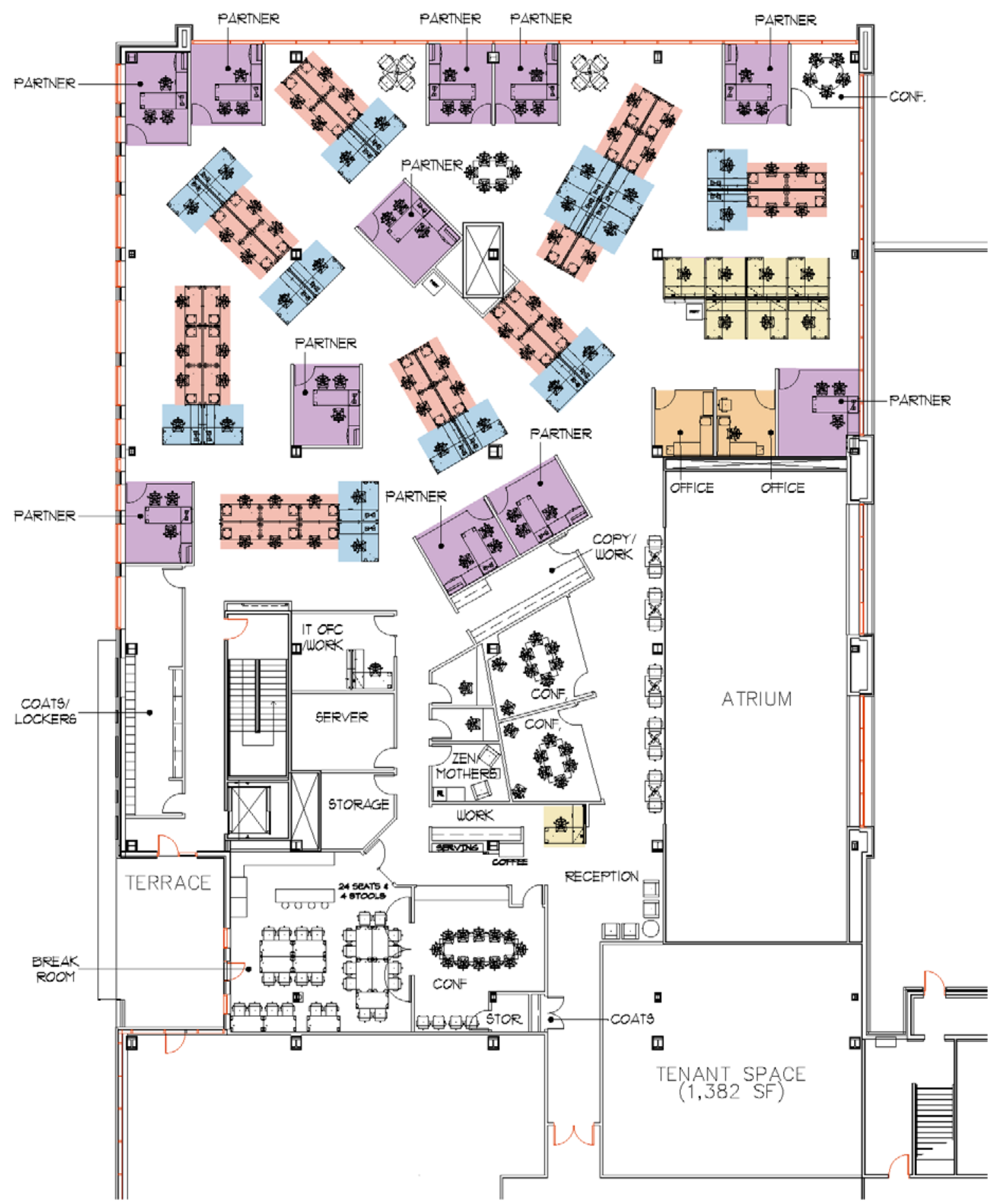

Figure 2. Floor plan of TeamDKB's new offices in Rochester. Interior architecture: SEI Design Group, Rochester. Office footprint is approximately 110 by $149 \mathrm{ft}$. 


\subsection{Lighting and Controls Description}

In the TeamDKB offices, LED luminaires provide most of the lighting for visual tasks in the open office space and private offices, and consist of recessed linear 2-inch-wide slots for direct lighting in offices with acoustical ceilings, pendant-mounted direct/indirect linear 2-inch-wide pendants in areas with exposed ceilings, square recessed downlights in other areas with acoustical ceilings, and cube-shaped pendant downlights in open ceiling areas. Floor-to-ceiling windows provide plentiful daylight except on short winter days.

OLED luminaires are primarily located in visually prominent areas: conference rooms, principal offices, break room, lounge table areas next to the building's atrium, entry corridors and reception desk. Amber OLED marker lights are used in the Zen/Mother's room (an interior space used for nursing mothers or staff dealing with migraines or other illness). A few angled OLED task lights add localized desk lighting in private offices, and two pendant lights add decorative touch to the copy room.

\subsection{Color of light}

TeamDKB, the architects, and the lighting designer settled on 3500 K CCT (neutral) color for LEDs, and $3000 \mathrm{~K}$ (warm) for the OLED products. All of the OLED products were provided with OLEDWorks panels, most being designed around those panels as a matter of product design, and some having been modified to accept the OLEDWorks panels even though the luminaire manufacturer originally designed its product line around LG Display panels.

\subsection{Luminaire power supply details}

OLEDWorks light engines require 24VDC power input. The power supplies and drivers used in the project came from a variety of sources and could be classified into two general types. Many luminaire manufacturers used the single panel drivers from OLEDWorks that require 24VDC power input. This is supplied by a transformer that converts 120VAC into 24VDC, which then feeds one or more drivers, which in turn regulates the current to the panels. Therefore, if there is a three-panel luminaire, there will be a single transformer, usually located above the ceiling, feeding three one-channel drivers.

The other common approach was to use a driver that accepted $120 \mathrm{~V}$ line voltage, and provided one or more outputs to control the OLED panels. These units could supply a higher-voltage, current-controlled power that could be used to drive several panels connected in series in the same luminaire.

Almost all OLED luminaires are connected to 0-10V wall-box raise/lower dimmers with on/off switch and either integral or remote vacancy sensor control.

\subsection{Lighting plan and lighting schedule}

The lighting plan and abbreviated luminaire schedule are shown in Figure 3. 


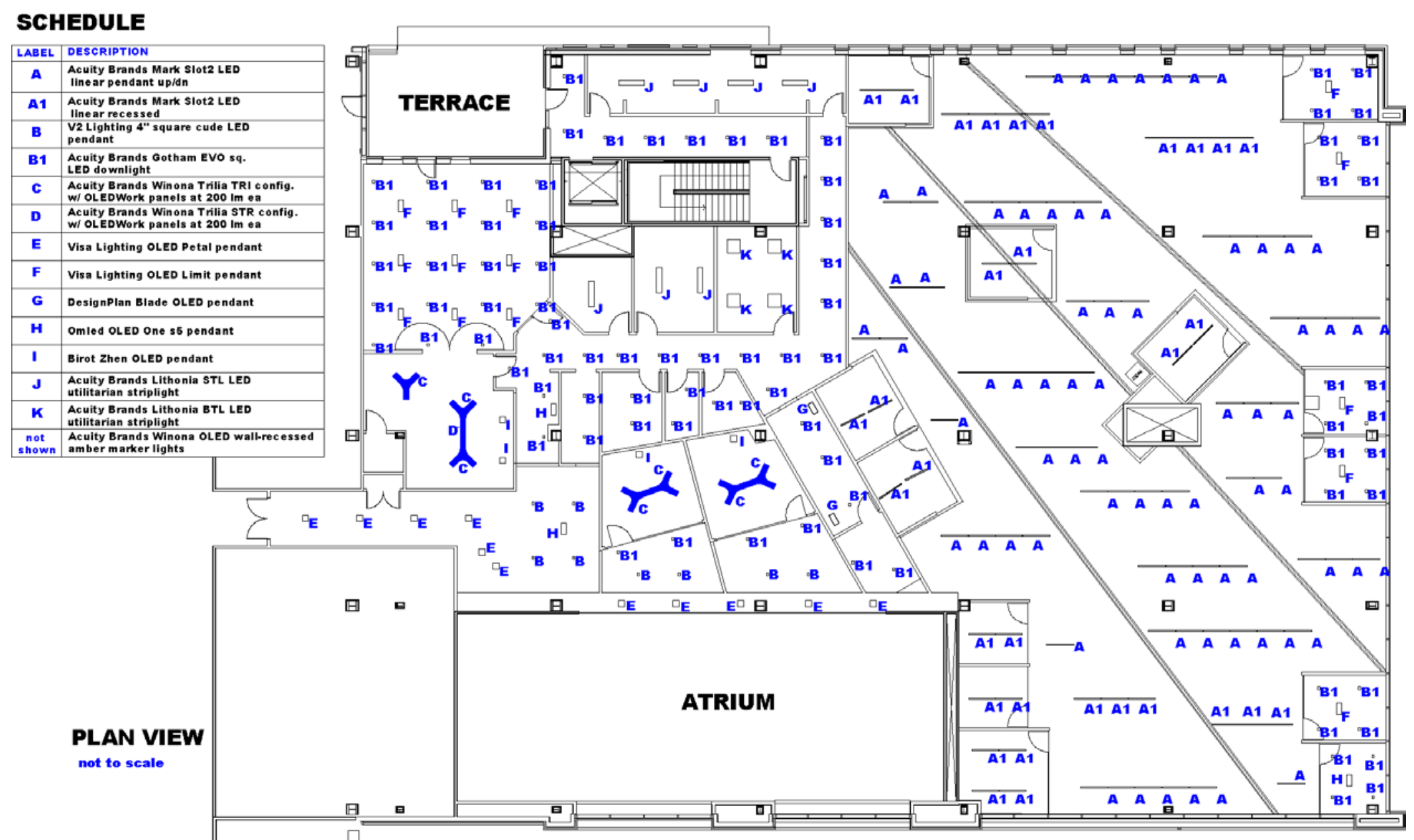

Figure 3. TeamDKB office lighting plan (not to scale), with abbreviated luminaire schedule. Graphics credit: PNNL. 


\subsection{Results}

PNNL visited TeamDKB's new offices on February 6, 2017, to observe the use of the space and lighting, collect lighting measurements, and interview staff members. The responses from the interviews from this visit were compared to interviews with the same staff members on June 3, 2016, in their previous offices equipped with recessed fluorescent troffers. The following describes these and other results of the visit.

\subsection{Details: Private offices, perimeter}

There are only 11 private offices in the floor plan, and they are partner offices or guest offices, with a glass wall facing outside, and a second glass wall for an open, welcoming appearance and to share daylight and views. Of these, seven are private offices around the perimeter of the space, designated for firm partners. The lighting consists of four recessed square LED downlights by Acuity Brands Gotham Lighting, one Visa Limit ${ }^{\mathrm{TM}}$ OLED pendant suspended above the desk, and one optional OLED task light commercialized by OLED Devices LLC (Figure 4). The downlights and the OLED pendant are both controlled by a single integral occupancy sensor/dimmer/switch mounted at the door, and dim together. Thus, it was not possible to measure the contribution to the room lighting from the OLED pendant alone. Table 1 lists the workplane illuminances measured at 30 inches above the floor on an approximate 3-foot grid of points 2-feet from outside walls, vertical illuminance on the computer screen as located by the user, and vertical illuminance on walls at a 5-foot height at three locations where artwork is most likely to be displayed. 


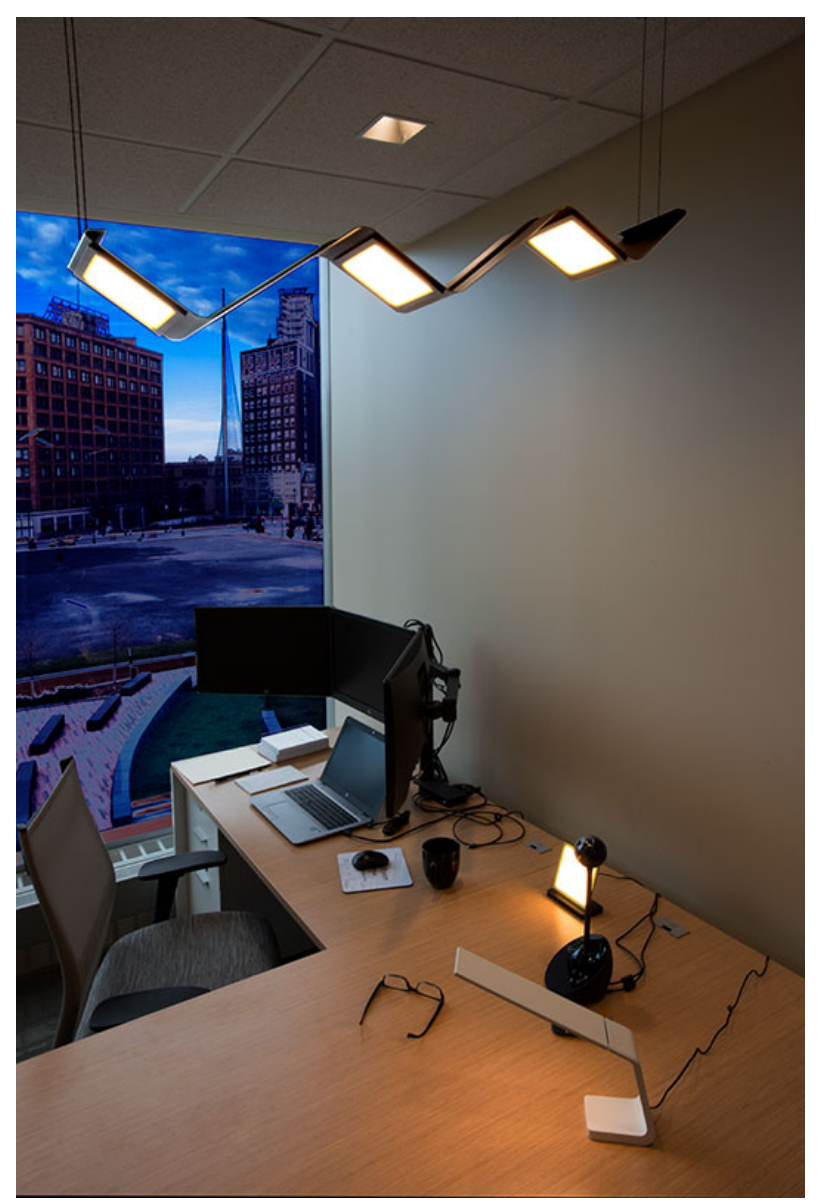

Figure 4. Perimeter office, showing recessed LED downlights, the Visa Limit ${ }^{\mathrm{TM}}$ OLED pendant light, and OLED Devices task light (in foreground). The glowing square on the desk is an award with printed text and images backlit by a single OLED lighting panel. Photo courtesy OLEDWorks LLC and DeJoy Knauf \& Blood, LLP.

\subsection{Details: Private offices, interior}

Interior offices have two adjacent glass walls. 8-foot-long, recessed 2-inch-wide linear LED slot lights with white diffusers provide ambient lighting. (Manufacturer's photometric reports show $863 \mathrm{~lm} / \mathrm{ft}$, $83 \mathrm{~lm} / \mathrm{W}, 42 \mathrm{~W}$ per 4-foot length.) Even though there is a white diffuser at the aperture, the light distribution is narrower than is normally produced by a diffuser because of special internal optics. This makes the luminaire more comfortable to view from higher angles between $45^{\circ}$ and $90^{\circ}$, than if the diffuser produced a more conventional cosine distribution. From directly below the luminaire (nadir), an approximate luminance of $27,000 \mathrm{~cd} / \mathrm{m}^{2}$ was measured (See Table 1 for measurements and luminance meter information), and about $13,500 \mathrm{~cd} / \mathrm{m}^{2}$ was measured from $45^{\circ}$ from nadir, indicating that due to the narrow beam control of the downward light, the luminance decreases by half as the angle of view changes from looking straight up into the recessed linear luminaire to viewing it from a more common viewing angle of $45^{\circ}$ from nadir.

In spite of this, multiple employees described these luminaires as uncomfortably bright. These luminaires are controlled by a wall-mounted $0-10 \mathrm{~V}$ wallbox dimmer/vacancy sensor, so they could be 
dimmed by the office occupant, although not all occupants interviewed were aware that they could dim their own office lighting to improve the comfort and reduce the light level. Occupants of interior private offices have the option of supplementing their desk-top lighting with an OLED task light. Table 1 shows 30-inch workplane illuminance values measured on an approximate 3-foot grid, 2 feet from outside walls; vertical illuminance on the occupant-located computer screen measured at 4 feet above the floor, and vertical illuminances on at 5 feet above the floor in three likely artwork locations.

\subsection{Details: Open office}

Open offices incorporate spines of workstation partitions that are 4 feet- 6 inches tall. These block the view of workstations on other spines, yet are not tall enough to block the daylight significantly (Figure 5). The spines provide enough isolation to give work teams a sense of group identity. Lighting is provided principally by daylight, supplemented with overhead direct/indirect linear LED pendants and matching recessed linear luminaires in suspended ceilings.

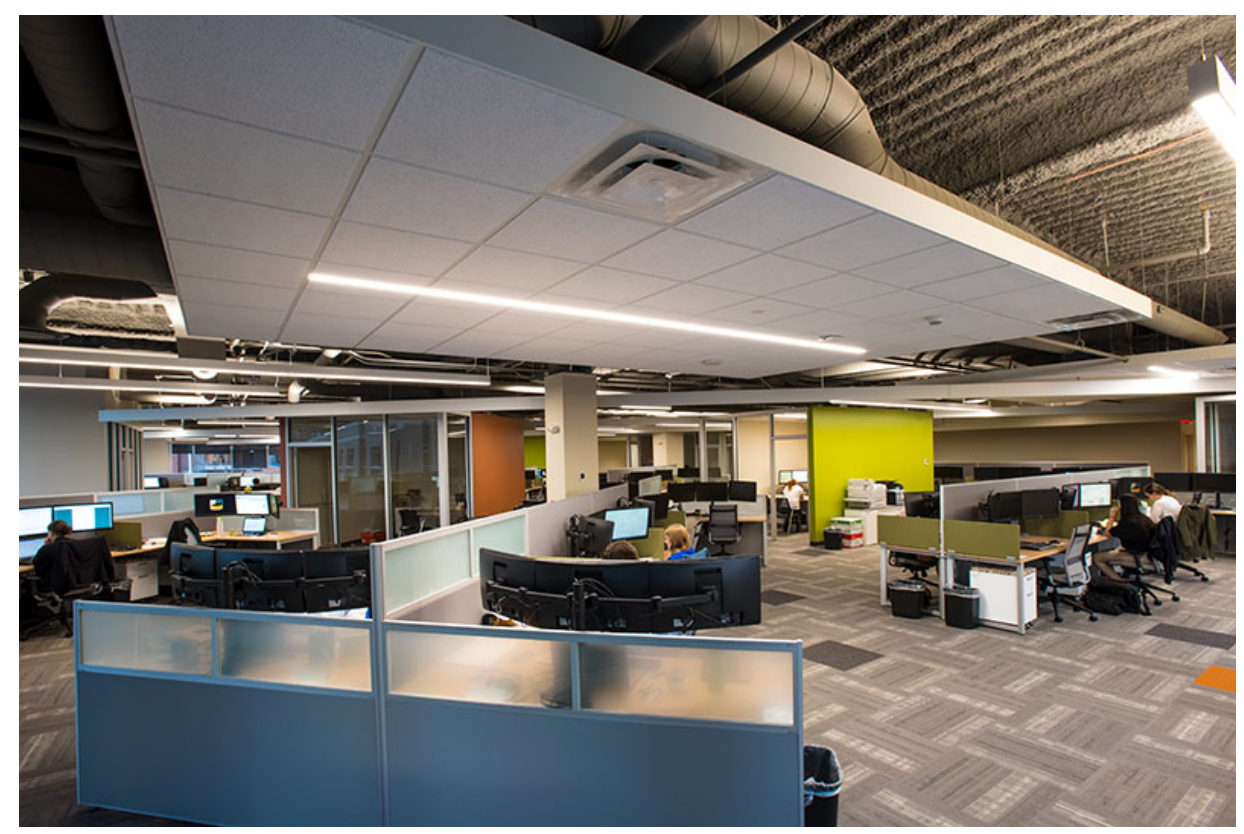

Figure 5. TeamDKB open office work stations located along linear partition spines. All narrow linear luminaires, recessed or pendant-mounted, use LEDs, delivering a measured CCT of $3476 \mathrm{~K}$ and a CRI of 82. Photo courtesy OLEDWorks LLC and DeJoy Knauf \& Blood, LLP.

The Acuity Brands Mark Slot2 LED pendants are only 2.5 inches wide, and incorporate a diffusing lens with sophisticated optics to reduce high-angle glare on the downward side and a batwing distribution to smooth out ceiling stripes on the uplight side. According to the manufacturer's specification sheet, they deliver 2066 lumens downward, and 2616 lumens upward per 4-foot length, and draw $51 \mathrm{~W}$ at full output. They use an eldoLED constant current driver, $0-10 \mathrm{~V}$ control, with dimming down to $0.1 \%$. The system efficacy is $92 \mathrm{~lm} / \mathrm{W}$.

The linear pendants suspended below white acoustical ceiling “clouds” deliver significant diffuse lighting reflected from the uplighted panels, which helps soften shadows on the floor and furniture, and makes faces easier and more pleasant to view because of the soft ambient lighting. The uplight from 
pendants suspended below unfinished ceilings are less effective for this purpose, because the exposed ducts are painted gray, as is the exposed ceiling's spray-on fireproofing material, absorbing approximately half the upward light.

Lighting measurements were taken after daylight hours and are reported in Table 1. Workplane horizontal illuminances were measured on desktops and on an approximate 3-foot grid at 30 inches above the floor, no closer than 2 feet from walls. Computer screen vertical illuminances were measured at 4 feet above the floor, and wall vertical illuminances were measured 5 feet above the floor in likely artwork locations.

\subsection{Details: Large conference room}

The conference room is entirely lighted with OLED products. A large Acuity Brands Winona ${ }^{\circledR}$ Trilia $^{\mathrm{TM}}$ luminaire with 56 panels (two 24-panel triangular sections connected by an 8-panel straight section) hovers above the conference table, with a single 24-panel triangular Trilia ${ }^{\mathrm{TM}}$ configuration in the corner of the room (Figure 6). These luminaires were designed for LG Display panels with a maximum luminance of $3000 \mathrm{~cd} / \mathrm{m}^{2}$, but were engineered for this project with the OLEDWorks Brite 2 panels capable of emitting $8300 \mathrm{~cd} / \mathrm{m}^{2}$. The maximum panel luminances are limited by the selected Acuity Brands eldoLED driver to approximately $6000 \mathrm{~cd} / \mathrm{m}^{2}$, or 200 lumens per panel ${ }^{1}$. This delivers more light in the room with fewer panels, at the risk of occupants perceiving the panels as excessively bright at their full output setting. However, the cosine distribution of light from panels seems to mitigate any perception of glare, since there were no complaints or comments by interviewed office staff. The conference room dimming setting was never found at full output during the GATEWAY site visit, so it could be that room occupants prefer lower light levels and lower panel luminances than available at maximum output.

The Trilia ${ }^{\mathrm{TM}}$ configurations use one eldoLED three-channel driver per triangle section and one per straight section, each driver channel powering four panels in series, two sets in parallel. All are controlled with a $0-10 \mathrm{~V}$ wallbox dimmer at the entrance wall. These drivers receive 120VAC input and deliver the needed DC current to the panels.

\footnotetext{
${ }^{1}$ The Acuity Brands OLED products are in transition at the time of this writing, and although OLEDWorks panels will be a standard offering in the future on some models, LG Display panels will continue to be offered as well.
} 


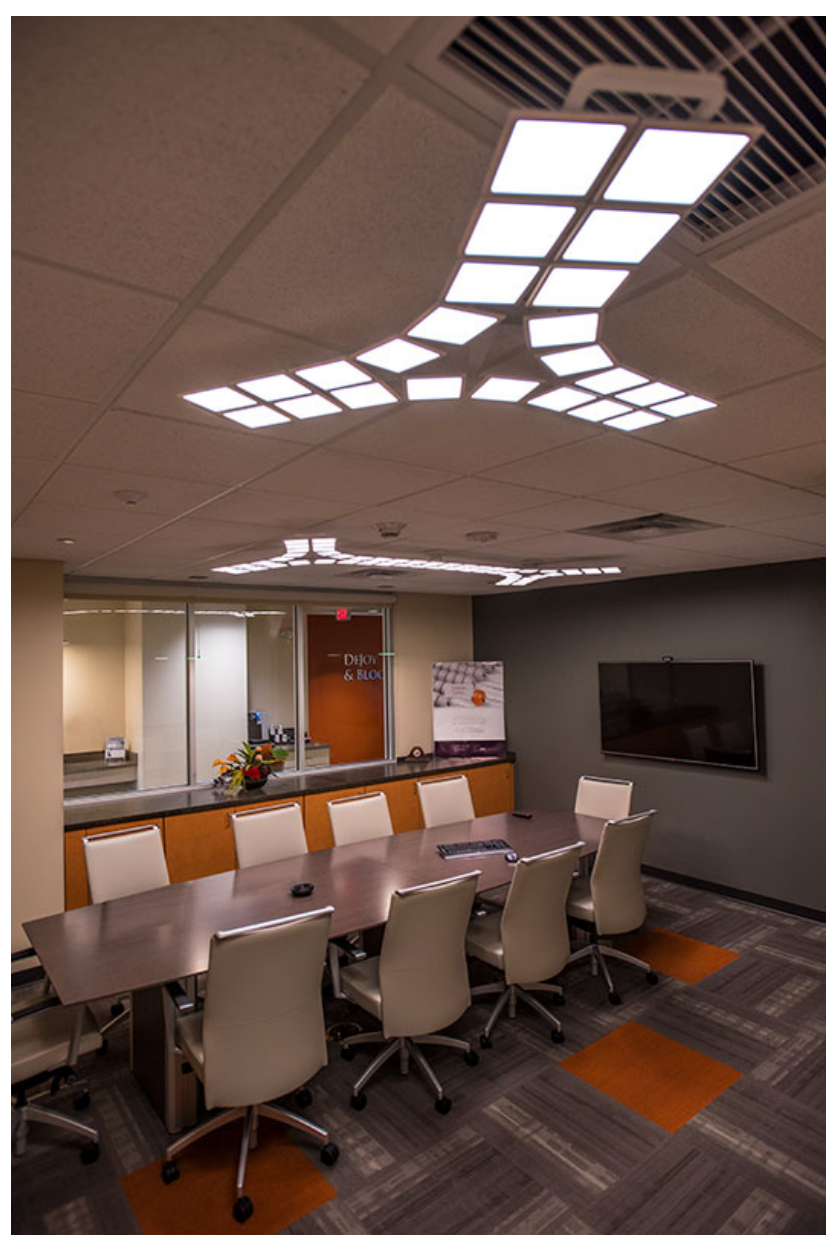

Figure 6. TeamDKB large conference room showing the 24-panel and 56-panel Acuity Brands Winona ${ }^{\circledR}$ Trilia $^{\mathrm{TM}}$ configurations, plus two single panel Birot Zhen pendants over the lower cabinets at the window wall. Photo courtesy OLEDWorks LLC and DeJoy Knauf \& Blood, LLP.

A linear cabinet along the window wall is lit with a pair of Birot Zhen pendants, each with a single OLEDWorks Brite 1 panel, on a separate control group from the Trilia ${ }^{\mathrm{TM}}$ pendant (Figure 7 and Figure 8). Each pendant is powered by a single transformer and single Philips OLED driver. 


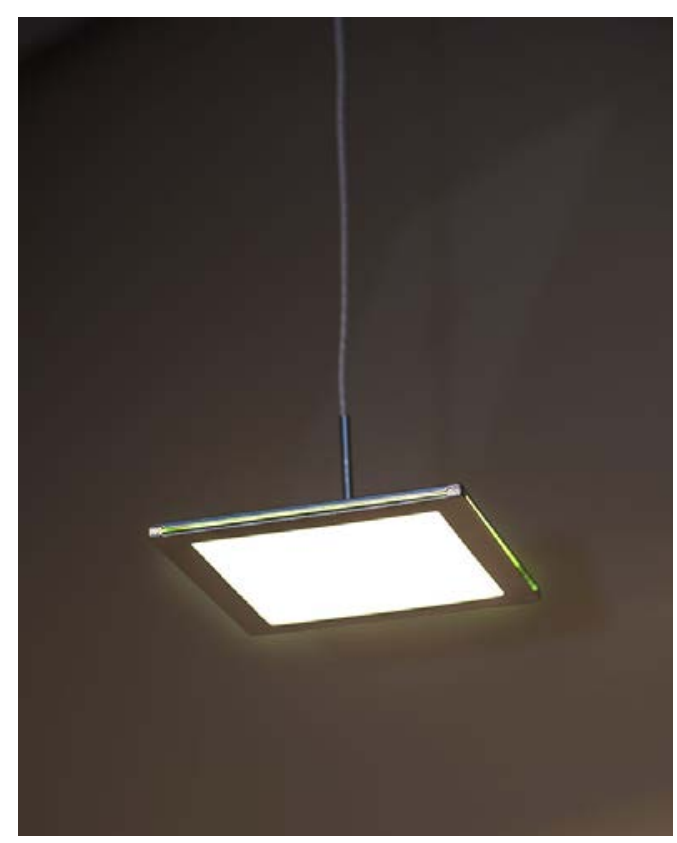

Figure 7. Birot Zhen single-panel OLED pendant. Photo courtesy OLEDWorks LLC and DeJoy Knauf \& Blood, LLP.

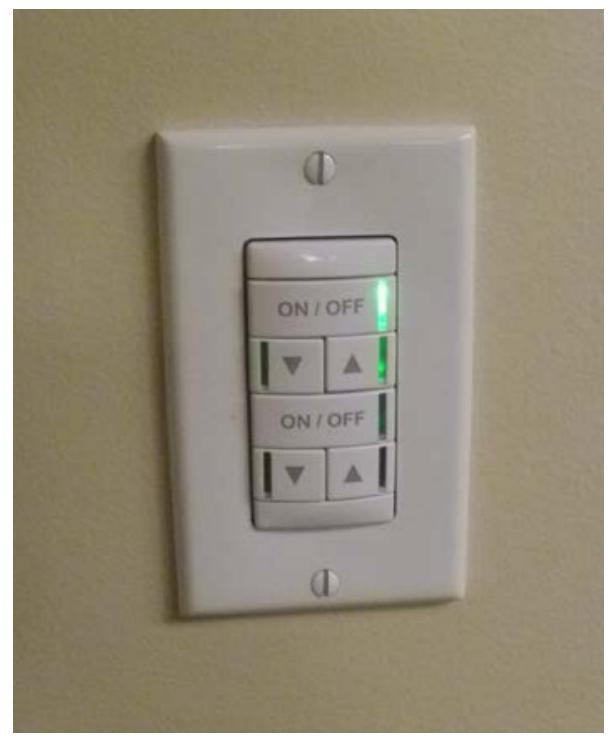

Figure 8. Wall control in large conference room, with separate raise/lower functions for the Acuity Brands Winona ${ }^{\circledR}$ Trilia ${ }^{\mathrm{TM}}$ pendants and the Birot Zhen pendants. Photo: PNNL.

One advantage of the OLED panels and their soft cosine light distribution is their ability to illuminate faces in a conference setting without harsh shadows. Room users reported that they use just the on/off switch to control the lighting in the room and seldom change the dimming settings because the light levels upon entry seem appropriate. PNNL found that the Trilia ${ }^{\mathrm{TM}}$ configuration over the conference table was dimmed to approximately $33 \%$ and $54 \%$ of its maximum output on two occasions (maximum luminance of $9318 \mathrm{~cd} / \mathrm{m}^{2}$, found dimmed to 3300 to $6000 \mathrm{~cd} / \mathrm{m}^{2}$ ). Table 1 shows illuminance and luminance values prorated to their maximum output values. Workplane illuminances were measured on the conference table, countertop, and corner table areas only, with measurement points spaced approximately 3 feet on 
center. Vertical illuminances on faces were measured at a height of 4 feet above the floor, at four cardinal seating locations at the conference table. Vertical illuminances on walls were measured 5 feet above the floor at likely artwork or markerboard locations in the room.

\subsection{Details: Small conference room}

There are two smaller conference rooms equipped with a single 48-panel Trilia ${ }^{\mathrm{TM}}$ configuration above the conference table (using two eldoLED three-channel drivers), and one Birot Zhen single panel pendant above a cabinet powered by a single 24VDC transformer and single-channel driver (Figure 9). There is a manual-on/vacancy sensor-off wall control with raise/lower function for dimming by occupants. Similar to the larger conference room, employees report that they seldom use the dimming option; however, in this case PNNL found the dimming settings at maximum output two separate times. Light levels are listed in Table 1. Illuminances were measured during daylight hours, both with and without electric lighting. Daylighting values were subtracted from the total to yield the electric lighting contributions. Workplane illuminances were measured at the conference table and countertop only. Vertical illuminances on faces were measured at 4 feet above the floor at seating locations at the conference table only; wall illuminances were measured in likely artwork or markerboard locations around the room, 5 feet above the floor.

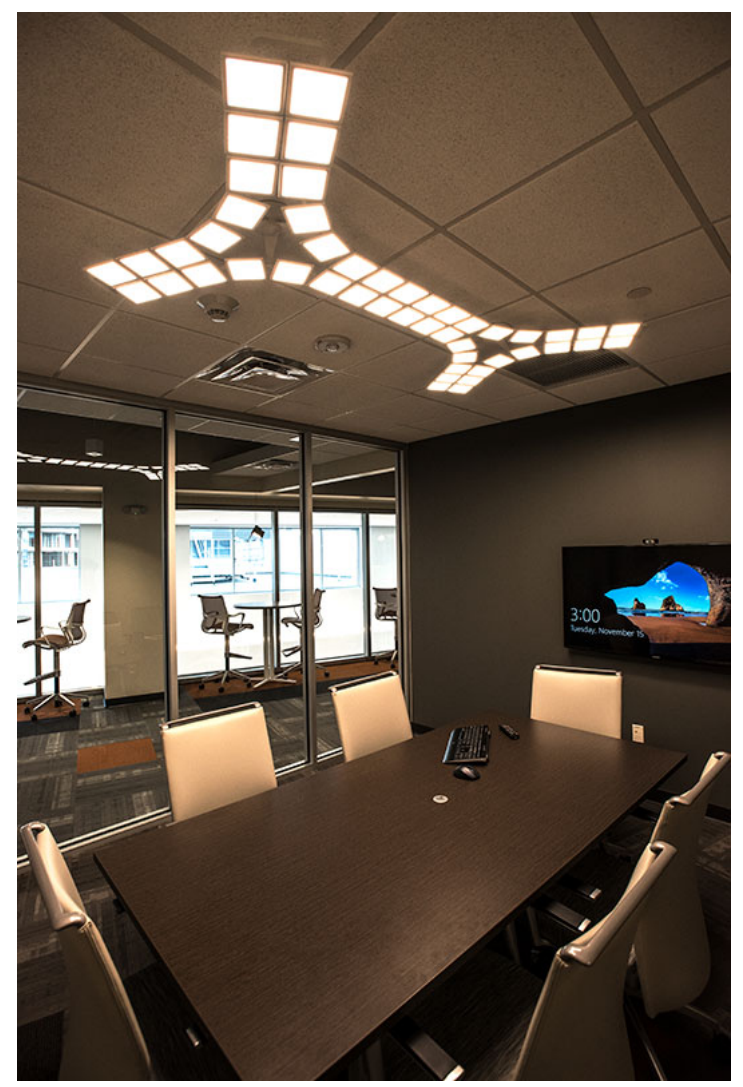

Figure 9. Smaller conference room showing 48-panel Acuity Brands Winona ${ }^{\circledR}$ Trilia ${ }^{\mathrm{TM}}$ pendant. Photo courtesy OLEDWorks LLC and DeJoy Knauf \& Blood, LLP. 


\subsection{Details: Break room}

The break room is an intentionally cheerful space with playful luminaires to provide a visual and psychological break from the workspace. A window wall looks to the west, and daylight is plentiful most of the day. Dimmable recessed square aperture LED downlights perform the bulk of the lighting work on counters and tables on gloomy days and outside of daylight hours on short winter days, but the luminaires that set the mood are the Visa Limit ${ }^{\mathrm{TM}}$ pendants with brushed aluminum undulating form and three OLED panels (Figure 10). At full output, the PNNL team measured an average of 329 lux from the downlights, and 109 lux from the pendants. Table 1 summarizes horizontal illuminances measured at a 30-inch workplane height at points spaced approximately 5 feet on center, with the grid points spaced 2 feet from the outer walls. Daylight values were subtracted from measurements of combined daylight and electric lighting.

The downlights and decorative OLED pendants are dimmed separately. Luminances of the OLED panels were measured at full output, and they averaged $7210 \mathrm{~cd} / \mathrm{m}^{2}$ when measured perpendicular to the panel, and $8310 \mathrm{~cd} / \mathrm{m} 2$ when measured from a $45^{\circ}$ angle from the panel. This is roughly the luminance of a bare T12 fluorescent lamp. Contrast that with average luminance measurements of the recessed LED downlights with white diffuser over the LED array from directly below $\left(199,000 \mathrm{~cd} / \mathrm{m}^{2}\right)$ and from a 45 degree angle $\left(112,000 \mathrm{~cd} / \mathrm{m}^{2}\right)$. The LED light engine produces higher light output than the OLED panels and is deeply regressed so that there is little chance for room users to experience this high luminance from normal viewing angles, but it illustrates that the lower luminance of the OLEDs allows them to be viewed directly more comfortably.

Two of the Visa Limit ${ }^{\mathrm{TM}}$ luminaires received CALiPER independent testing before they were installed, which shows that on average each delivers 821 lumens and draws $27.7 \mathrm{~W}$, for a delivered 29.6 $\mathrm{lm} / \mathrm{W}$ when new with 24VDC input power. The efficiency of the transformer is estimated at $86 \%$, increasing the system input wattage to $32.2 \mathrm{~W}$, for a system efficacy of approximately $25.5 \mathrm{~lm} / \mathrm{W}$. This is comparable to a low-efficacy decorative fluorescent luminaire. (Visa Lighting will be offering this product with the higher efficacy Brite 2 panels in the near future.) 


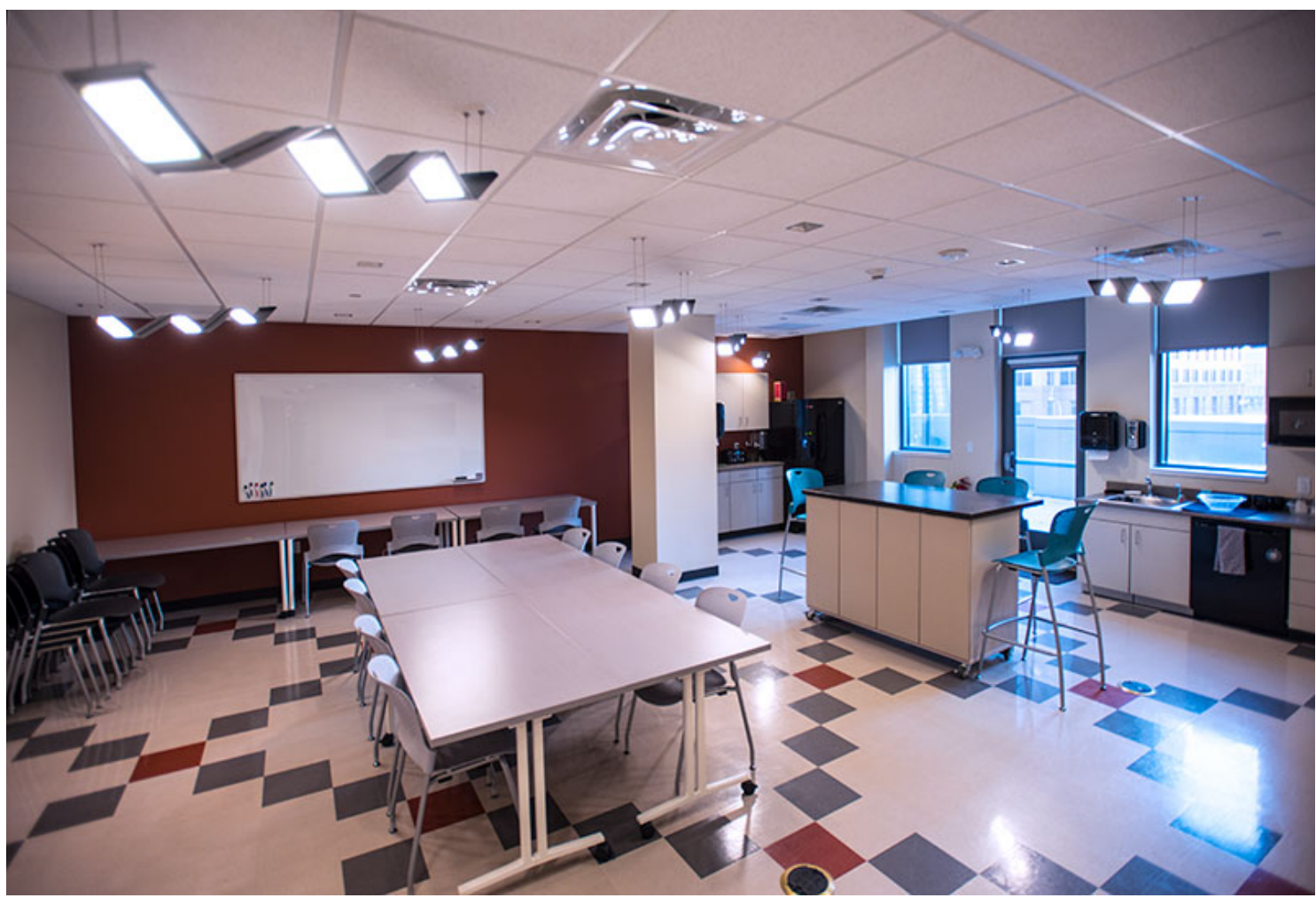

Figure 10. The TeamDKB break room showing the recessed square LED downlights and the playful Visa Limit ${ }^{\mathrm{TM}}$ pendants. Photo courtesy OLEDWorks LLC and DeJoy Knauf \& Blood, LLP.

\subsection{Details: Zen/Mother's room}

TeamDKB has young women among its workforce and created a private room for nursing mothers. The room is also utilized by team members who may need a quiet place to rest and recharge throughout the day. They have since learned that employees dealing with headaches or migraines also appreciate this room. It is small, private, and equipped both with recessed square 3500K white LED downlights, but also amber OLED marker lights, recessed in walls near the ceiling (Figure 11, Figure 12). Switched separately, the amber light is reportedly relaxing for occupants, and is also reported to be as effective as darkness for the staff migraineurs. (No attempt was made to measure or verify these effects.) The downlights produce an average of 200 horizontal lux on a 30-inch plane, while the amber marker lights produce 4.5 lux (Table 1). 


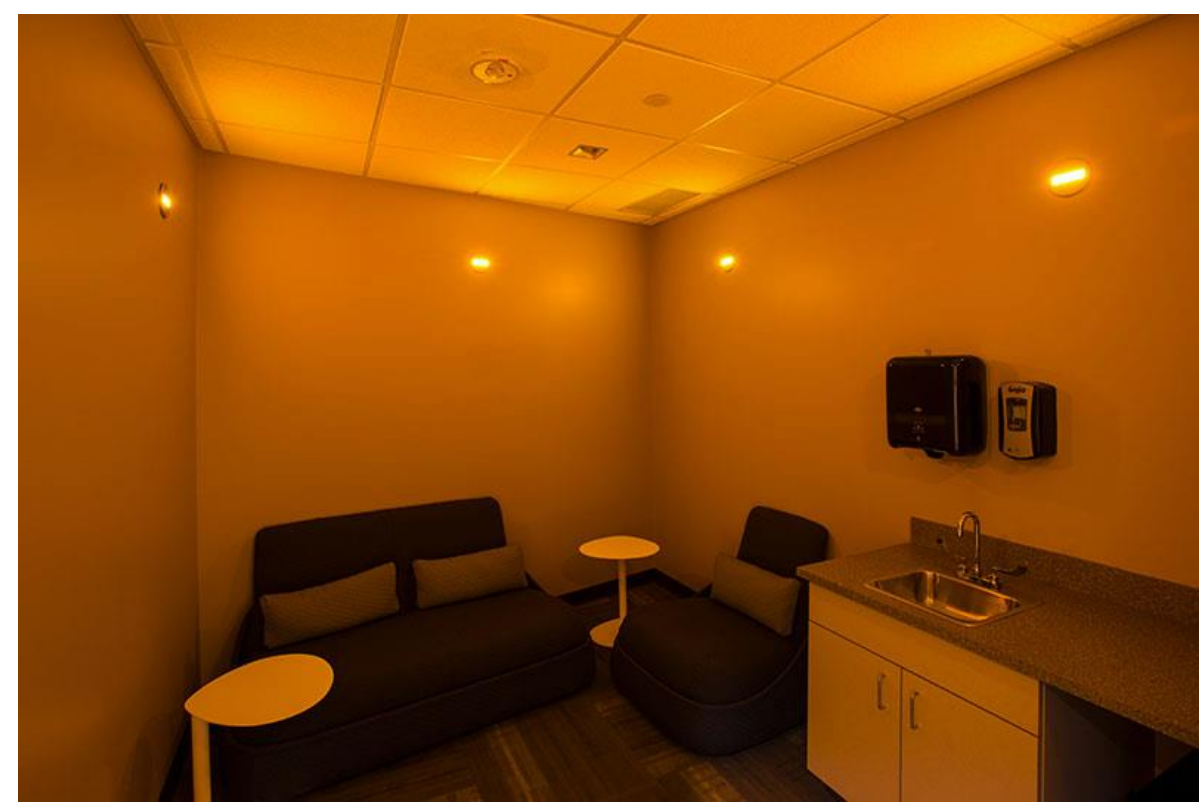

Figure 11. The Zen/Mother's Room, with only the amber OLED recessed marker lights in use. Photo courtesy OLEDWorks LLC and DeJoy Knauf \& Blood, LLP.

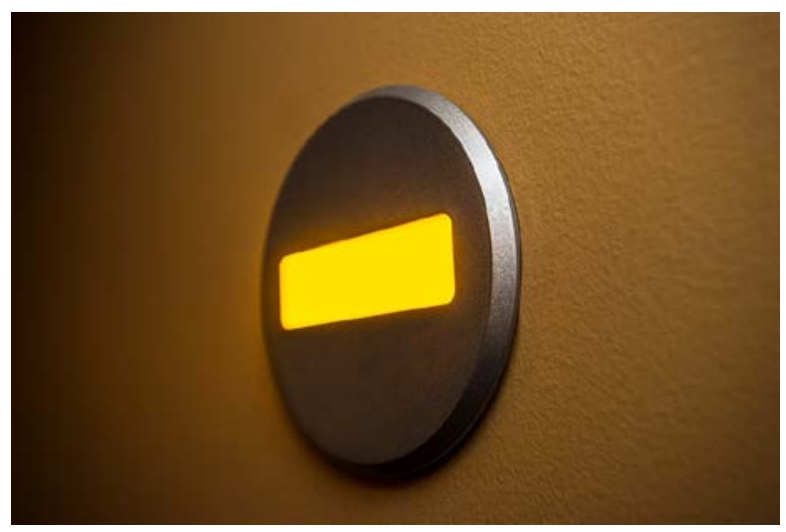

Figure 12. The recessed Amber OLED marker light custom made by Acuity Brands Winona ${ }^{\circledR}$ Lighting. Photo courtesy OLEDWorks LLC and DeJoy Knauf \& Blood, LLP.

\subsection{Details: Copy room}

Copy rooms are generally utilitarian in function and appearance, but in addition to recessed LED downlights, TeamDKB selected two OLED five-panel glass pendants from Designplan to dress up the room and provide softening light for faces and objects (Figure 13). The "Blade" luminaire uses five OLEDWorks Brite 1 panels behind a 3/4-inch-thick clear glass shield. The transformer and driver are located above the accessible ceiling, and the power to the panels is conducted over the support cables, enabling a sleek and light-weight look, with no exposed power cords. The luminaire draws $54 \mathrm{~W}$ and delivers 1215 lumens according to independent CALiPER testing, delivering $22.5 \mathrm{~lm} / \mathrm{W}$ at $120 \mathrm{~V}$ AC input. The panel luminance averages $7215 \mathrm{~cd} / \mathrm{m}^{2}$. Illuminances were not measured in this room because both downlights and OLED pendants are switched together, so it was not possible to separate the contributions from each system. 


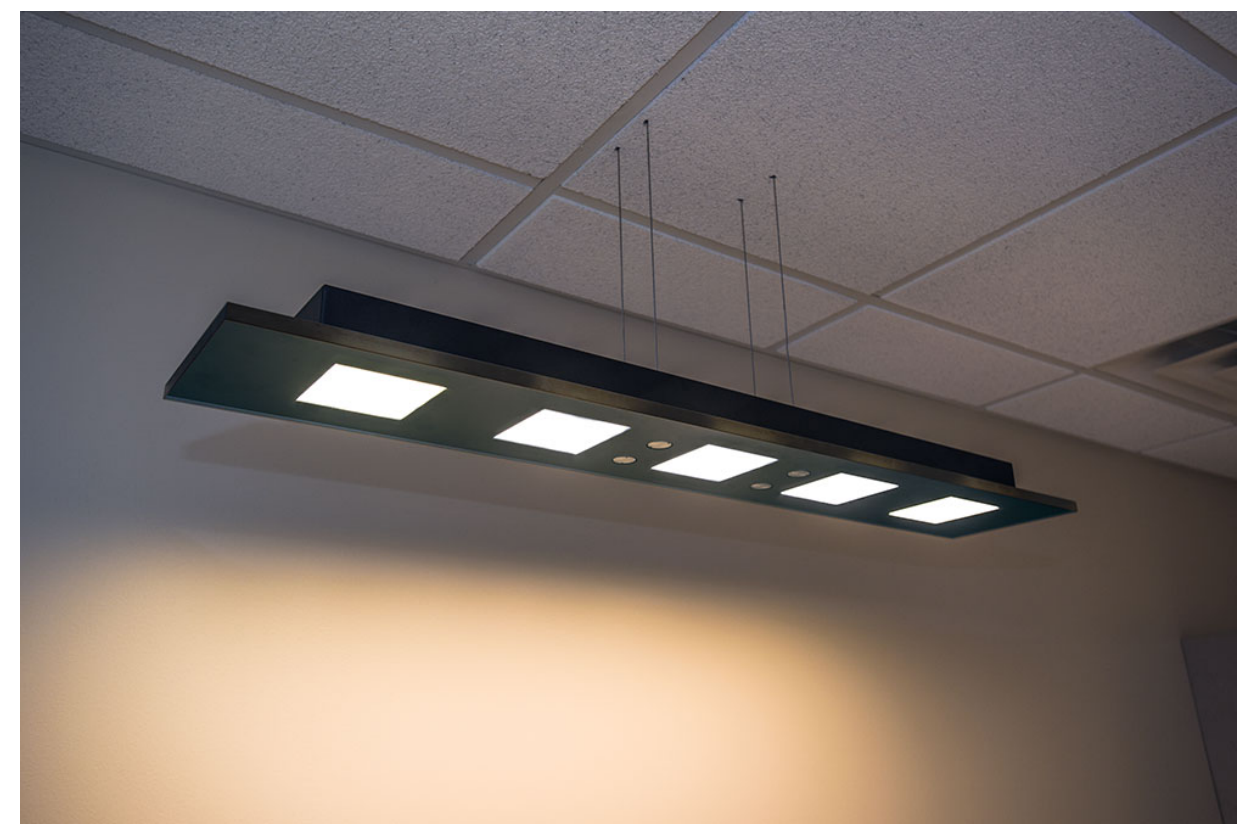

Figure 13. Closeup of the Designplan "Blade" luminaires suspended in the copy room. Photo courtesy OLEDWorks LLC and DeJoy Knauf \& Blood, LLP.

\subsection{Details: Lounge near atrium}

This is the area employees love to show off to visitors. High-top lounge tables off the main corridor are individually illuminated with a single Visa Lighting Petal ${ }^{\mathrm{TM}}$ pendant containing three OLEDWorks Brite 1 panels (Figure 14). Each Petal ${ }^{\mathrm{TM}}$ pendant has three drivers located in the junction box to which the canopy is mounted, one driver for each panel in the luminaire. The pendant delivers roughly 700 downward lumens drawing $34 \mathrm{~W}$, according to the manufacturer's photometric files. The PNNL team measured average panel luminances of $8162 \mathrm{~cd} / \mathrm{m}^{2}$ perpendicular to the panel and $8989 \mathrm{~cd} / \mathrm{m}^{2}$ from a $45^{\circ}$ angle. However, in spite of the $10 \%$ difference in measured luminance, interviewed employees saw no visible difference in "brightness" or color appearance from different viewing angles. The Petal ${ }^{\mathrm{TM}}$ pendant delivers 234 lx average to the table top, measured at the center and edge of the high-top table. Additional lighting is provided by recessed LED downlights, suspended LED “cube” pendants, and daylight borrowed from the building's atrium through the windows on the right (Figure 15). See Table 1 for more data. 


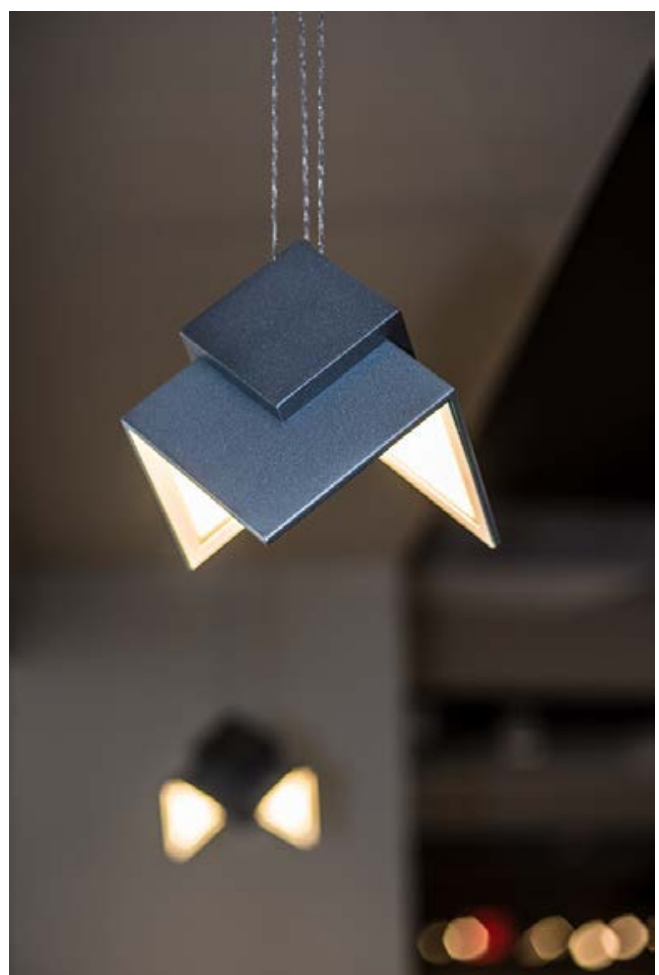

Figure 14. Closeup of the Visa Lighting Petal ${ }^{\mathrm{TM}}$ pendant. Photo courtesy OLEDWorks LLC and DeJoy Knauf \& Blood, LLP.

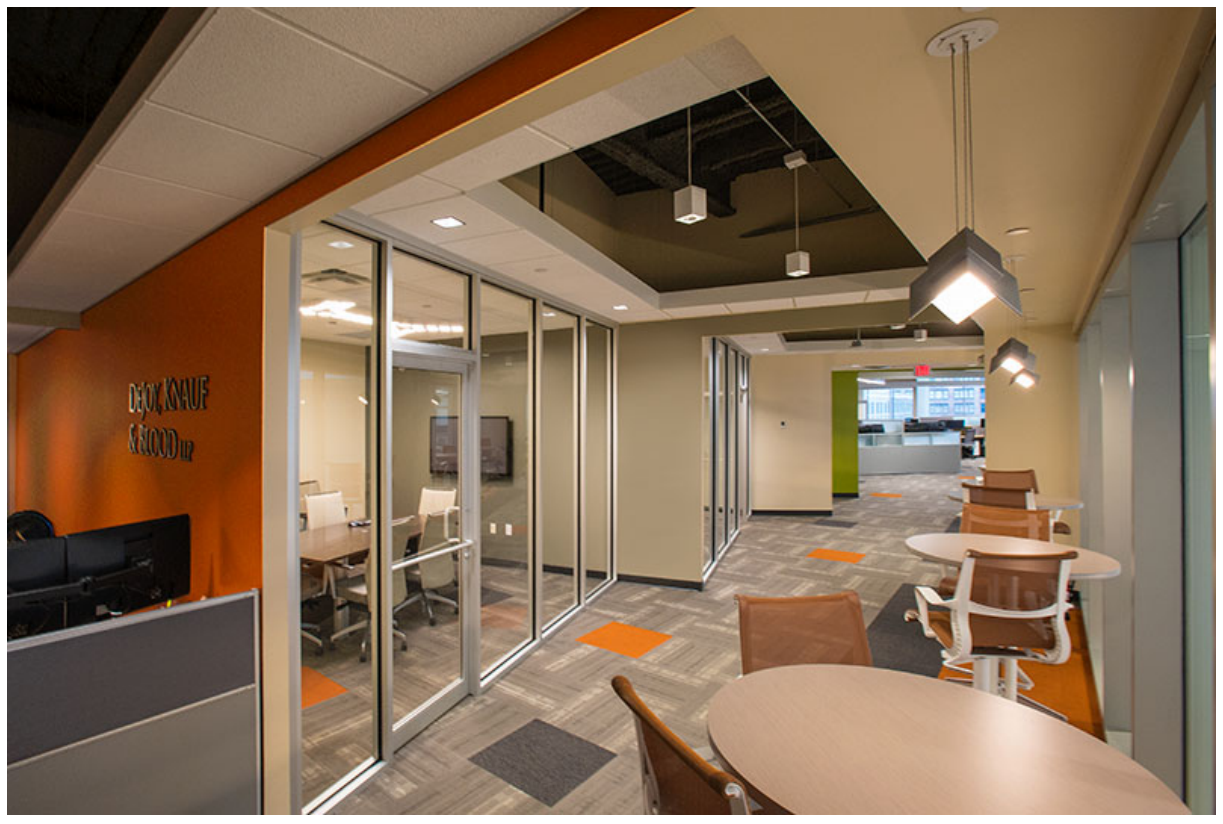

Figure 15. Visa Lighting Petal ${ }^{\text {TM }}$ OLED pendants suspended above high-top tables in a casual lounge area off a main corridor. A small conference room equipped with OLED configuration is visible through the windows on the left. The square recessed downlights and cube pendants use LED sources. Photo courtesy OLEDWorks LLC and DeJoy Knauf \& Blood, LLP. 


\subsection{Details: Entry corridor}

Four Visa Lighting Petal ${ }^{\mathrm{TM}}$ pendants also greet visitors entering the TeamDKB offices, delivering an average of 95 lux at the floor and 75 lux on walls at a 5-foot height. OLED panels deliver soft highlighting to the walls where TeamDKB plans to display artwork (Figure 16). Table 1 shows illuminances measured on the floor in the center of the corridor, averaging values at points both below and between pendants. Similarly, vertical illuminances on walls were measured at likely artwork locations, 5 feet above the floor, in line with the pendants and in between the pendants.

The reception desk has one five-panel OMLED pendant with a frosted glass diffusing panel. The OMLED pendant is unique in that the driver electronics are integrated into the luminaire glass, so there is no separate driver between the transformer and the glass luminaire housing. The frosted glass reduces the contrast between the glow of the panel through the glass and the surrounding glow of the glass, effectively reducing the apparent brightness (Figure 17). The luminance of the panel through the glass averages $3447 \mathrm{~cd} / \mathrm{m}^{2}$, and the frosted edge averages $446 \mathrm{~cd} / \mathrm{m}^{2}$, for a contrast ratio of less than 8 to 1 . Additional lighting measurements were not taken in the reception area because the lighting from the OLED pendant could not be isolated from other luminaires.

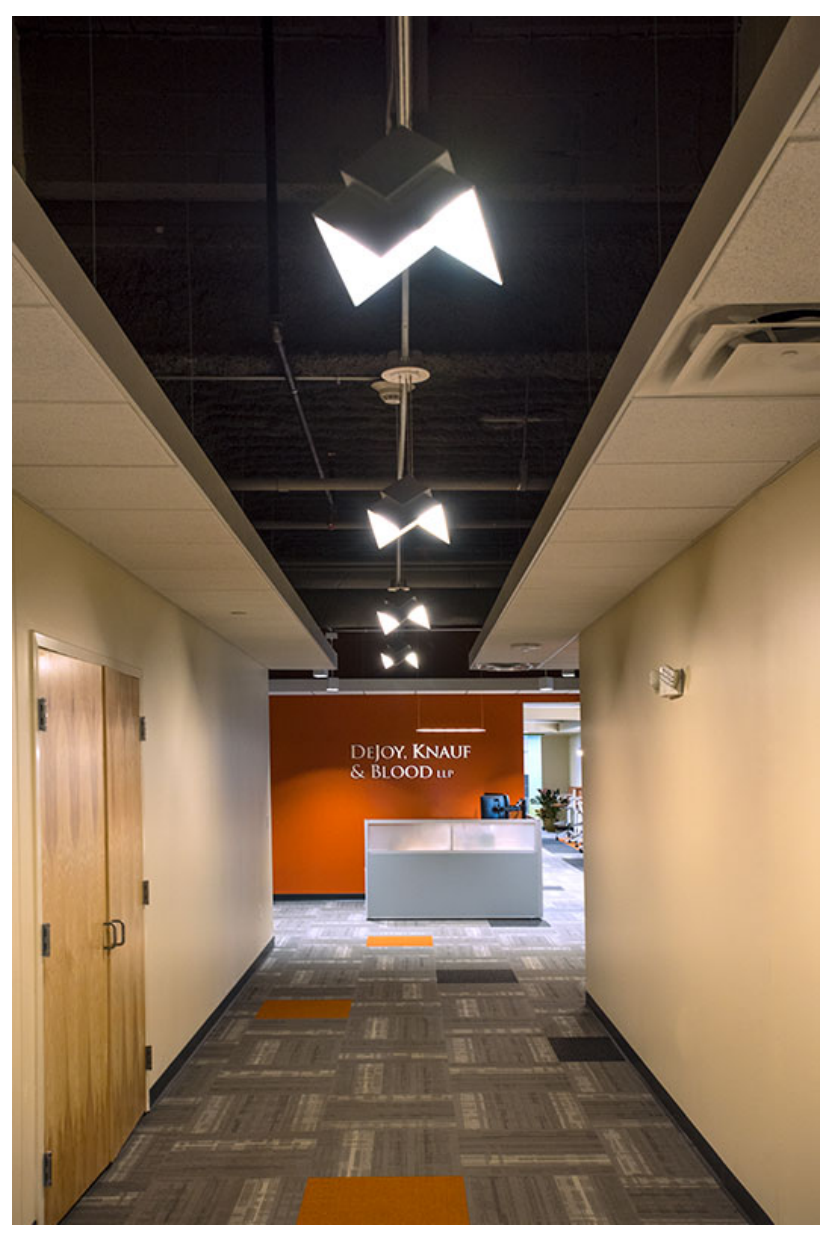

Figure 16. Entry corridor to DKB offices showing four Visa Lighting Petal ${ }^{\mathrm{TM}}$ pendants and a five-panel OMLED One s5 pendant above the reception desk. Photo courtesy OLEDWorks LLC and DeJoy Knauf \& Blood, LLP. 


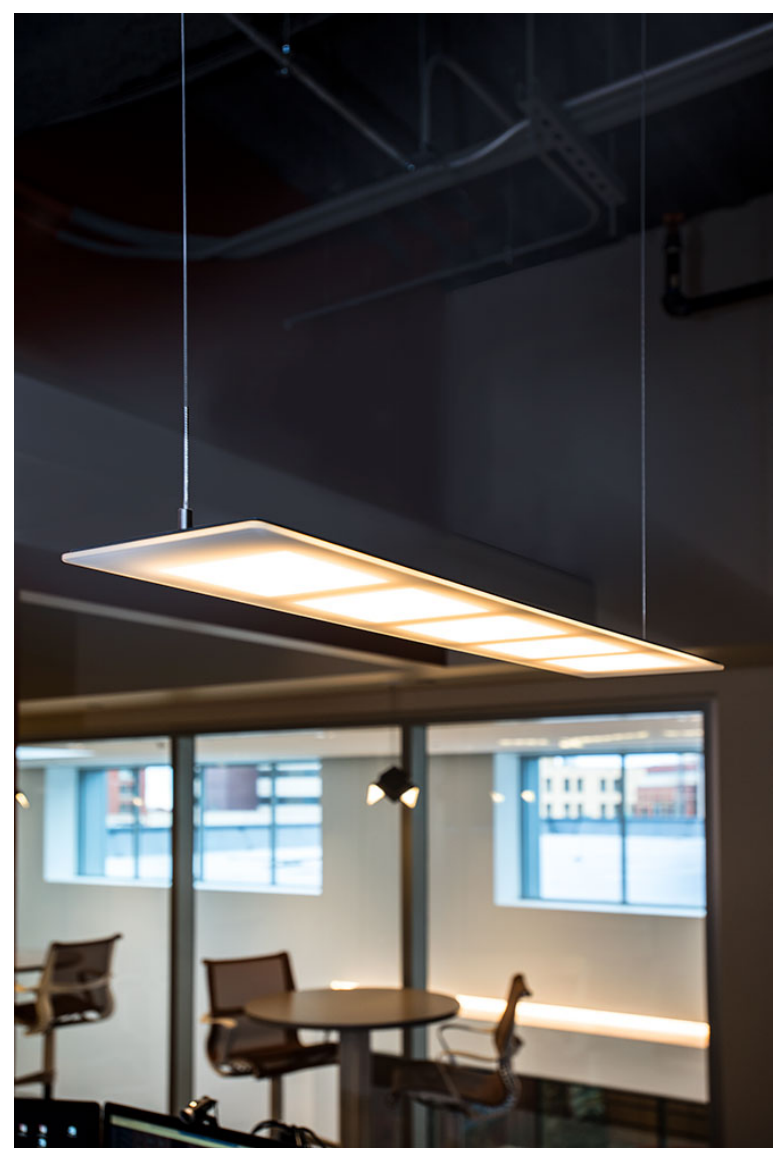

Figure 17. Closeup view of the OMLED One s5 pendant suspended above reception desk. Photo courtesy OLEDWorks LLC and DeJoy Knauf \& Blood, LLP.

\subsection{Details: Task light}

Occupants of private offices have the option of using OLED task lights on their desks, incorporating a 70 by 260 mm OLEDWorks Keuka OLED module with integral driver, available from OLED Devices. These lights operate on wall-plug 24VDC transformer/power packs. According to the documentation provided with the Ascend lamp by OLED Devices, the task light delivers 300 lumens, the system draws $8 \mathrm{~W}$ including the efficiency of the transformer and integral driver, for a system efficacy of $37.5 \mathrm{~lm} / \mathrm{W}$ (Figure 18). The angled task light reaches only 8 inches above the desk, and produces a soft-edged pool of light on the desk that is roughly 3 feet in diameter; producing 1380 lux directly under the angled lens and 120 lux at the edge of the pool of light. 


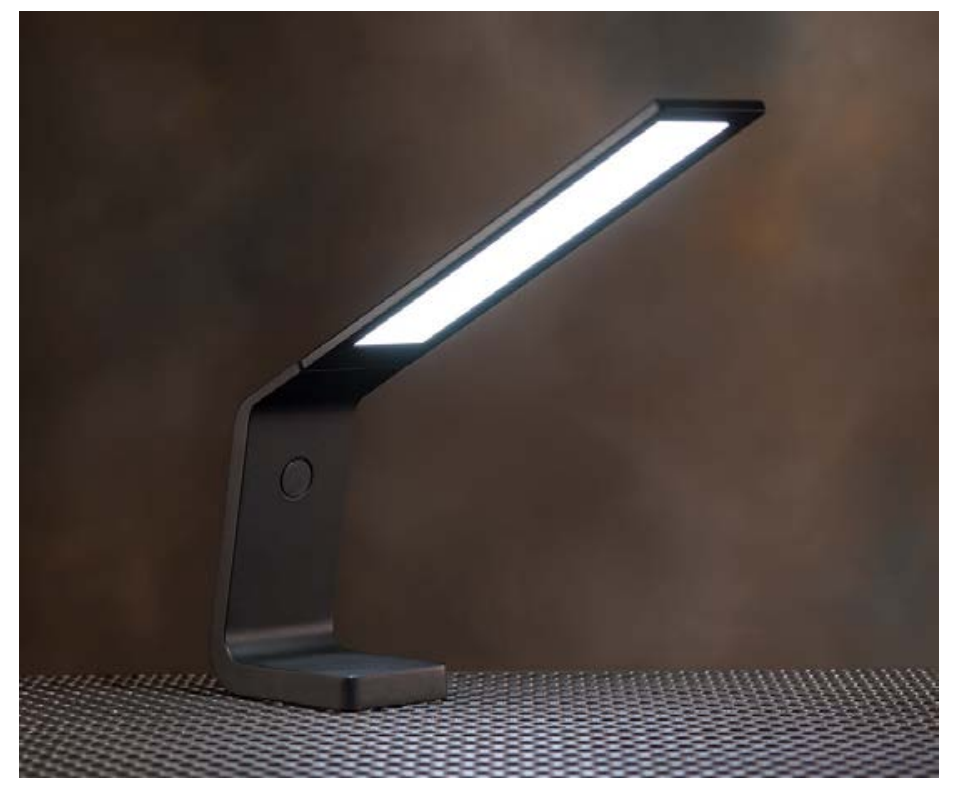

Figure 18. Closeup of Ascend task light by OLED Devices, used in private offices. Photo courtesy OLEDWorks LLC and DeJoy Knauf \& Blood, LLP. 
Table 1. Summary of illuminance and luminaire luminance values measured in TeamDKB office spaces, using a Konica-Minolta T-10A illuminance meter (calibration date 7/8/2016), and a Minolta LS-110 1/3 $3^{\circ}$ luminance meter (uncalibrated). Luminances were measured from a distance of 24 to 48 inches, with the $1 / 3^{\circ}$ capture angle completely within the luminous area of the panel.

\begin{tabular}{|c|c|c|c|c|c|c|c|c|c|c|c|c|c|c|c|}
\hline \multirow[b]{2}{*}{ Space } & \multirow[b]{2}{*}{ Luminaire Types } & \multicolumn{3}{|c|}{$\begin{array}{c}\text { Horizontal } \\
\text { illuminances in lux } \\
\text { at 30" work plane } \\
\text { u.o.n. }\end{array}$} & \multicolumn{3}{|c|}{$\begin{array}{c}\text { Vertical Illuminances } \\
\text { in lux on walls at } 5^{\prime} \\
\text { above floor }\end{array}$} & \multicolumn{3}{|c|}{$\begin{array}{c}\text { Vertical illuminance } \\
\text { in lux on faces at } \\
\text { conf. table }\end{array}$} & \multicolumn{3}{|c|}{$\begin{array}{c}\text { Vertical illuminance } \\
\text { in lux on computer } \\
\text { screens, 4' aff }\end{array}$} & \multicolumn{2}{|c|}{$\begin{array}{l}\text { Luminaire luminance } \\
\left(\mathrm{cd} / \mathrm{m}^{2}\right)\end{array}$} \\
\hline & & Min & Avg & Max & Min & Avg & Max & Min & Avg & Max & Min & Avg & Max & Nadir & $45^{\circ}$ \\
\hline \multirow{3}{*}{$\begin{array}{l}\text { Private offices, } \\
\text { perimeter }\end{array}$} & \multirow{3}{*}{$\begin{array}{l}\text { (4) recessed LED downlights } \\
\text { (1) Visa Limit }{ }^{\mathrm{TM}} \text { OLED } \\
\text { pendant } \\
\text { OLED desk lamp (not ON) }\end{array}$} & \multirow{3}{*}{250} & \multirow{3}{*}{467} & \multirow{3}{*}{581} & \multirow{3}{*}{180} & \multirow{3}{*}{215} & \multirow{3}{*}{254} & \multirow{3}{*}{$\mathrm{n} / \mathrm{a}$} & \multirow{3}{*}{$\mathrm{n} / \mathrm{a}$} & \multirow{3}{*}{$\mathrm{n} / \mathrm{a}$} & & \multirow{3}{*}{143} & & 198,600 & 112,300 \\
\hline & & & & & & & & & & & & & & 7210 & 8310 \\
\hline & & & & & & & & & & & & & & $\mathrm{n} / \mathrm{a}$ & $\mathrm{n} / \mathrm{a}$ \\
\hline $\begin{array}{l}\text { Private offices, } \\
\text { interior }\end{array}$ & $\begin{array}{l}\text { (1) Acuity Brands Mark } \\
\text { recessed linear LED slot }\end{array}$ & 370 & 561 & 822 & 213 & 315 & 511 & $\mathrm{n} / \mathrm{a}$ & $\mathrm{n} / \mathrm{a}$ & $\mathrm{n} / \mathrm{a}$ & & 255 & & 27,200 & 13,500 \\
\hline Open offices & $\begin{array}{l}\text { Acuity Brands Mark pendant } \\
\text { direct/indirect LED linear } \\
\text { luminaires }\end{array}$ & 163 & 450 & 775 & 99 & 236 & 287 & $\mathrm{n} / \mathrm{a}$ & $\mathrm{n} / \mathrm{a}$ & $\mathrm{n} / \mathrm{a}$ & 174 & 257 & 311 & $\mathrm{n} / \mathrm{a}$ & $\mathrm{n} / \mathrm{a}$ \\
\hline \multirow{3}{*}{$\begin{array}{l}\text { Large conference } \\
\text { room* }\end{array}$} & $\begin{array}{l}\text { (1) Acuity Brands Winona }{ }^{\circledR} \\
\text { Trilia }^{\mathrm{TM}} \text { 56-OLED-panel } \\
\text { configuration }\end{array}$ & \multirow{3}{*}{287} & \multirow{3}{*}{440} & \multirow{3}{*}{894} & \multirow{3}{*}{141} & \multirow{3}{*}{248} & \multirow{3}{*}{371} & \multirow{3}{*}{380} & \multirow{3}{*}{508} & \multirow{3}{*}{580} & \multirow{3}{*}{$\mathrm{n} / \mathrm{a}$} & \multirow{3}{*}{$\mathrm{n} / \mathrm{a}$} & \multirow{3}{*}{$\mathrm{n} / \mathrm{a}$} & 5860 & 6350 \\
\hline & $\begin{array}{l}\text { (1) Acuity Brands Winona }{ }^{\circledR} \\
\text { Trilia' }^{\mathrm{TM}} \text { 24-OLED-panel tri- } \\
\text { section }\end{array}$ & & & & & & & & & & & & & $\mathrm{n} / \mathrm{a}$ & $\mathrm{n} / \mathrm{a}$ \\
\hline & $\begin{array}{l}\text { (2) Birot Zhen single-OLED } \\
\text { panel pendants }\end{array}$ & & & & & & & & & & & & & 7000 & 7590 \\
\hline \multirow{2}{*}{$\begin{array}{l}\text { Small conference } \\
\text { room }\end{array}$} & $\begin{array}{l}\text { (1) Acuity Brands/ Winona }{ }^{\circledR} \\
\text { Trilia }^{\mathrm{TM}} \text { 48-OLED-panel } \\
\text { configuration (two tri-sections) }\end{array}$ & 623 & 684 & 727 & 147 & 244 & 358 & 350 & 386 & 443 & $\mathrm{n} / \mathrm{a}$ & $\mathrm{n} / \mathrm{a}$ & $\mathrm{n} / \mathrm{a}$ & 5600 & 5910 \\
\hline & $\begin{array}{l}\text { (1) Birot Zhen single OLED } \\
\text { panel pendant }\end{array}$ & & & & & & & & & & & & & 6470 & 7450 \\
\hline Break room & $\begin{array}{l}\text { (19) Acuity Brands Gotham } \\
\text { recessed LED square } \\
\text { downlights }\end{array}$ & 328 & 329 & 330 & $\mathrm{n} / \mathrm{a}$ & $\mathrm{n} / \mathrm{a}$ & $\mathrm{n} / \mathrm{a}$ & $\mathrm{n} / \mathrm{a}$ & $\mathrm{n} / \mathrm{a}$ & $\mathrm{n} / \mathrm{a}$ & $\mathrm{n} / \mathrm{a}$ & $\mathrm{n} / \mathrm{a}$ & $\mathrm{n} / \mathrm{a}$ & 198,600 & 112,300 \\
\hline & $\begin{array}{l}\text { (9) Visa Limit }{ }^{\mathrm{TM}} \text { OLED } \\
\text { pendants }\end{array}$ & 5 & 109 & 201 & $\mathrm{n} / \mathrm{a}$ & $\mathrm{n} / \mathrm{a}$ & $\mathrm{n} / \mathrm{a}$ & $\mathrm{n} / \mathrm{a}$ & $\mathrm{n} / \mathrm{a}$ & $\mathrm{n} / \mathrm{a}$ & $\mathrm{n} / \mathrm{a}$ & $\mathrm{n} / \mathrm{a}$ & $\mathrm{n} / \mathrm{a}$ & 7210 & 8310 \\
\hline & $\begin{array}{l}\text { (2) Acuity Brands Gotham } \\
\text { EVO® square recessed LED } \\
\text { downlights }\end{array}$ & 100 & 200 & 300 & & & & & & & & & & $\mathrm{n} / \mathrm{a}$ & $\mathrm{n} / \mathrm{a}$ \\
\hline Zen/Mother’s room & $\begin{array}{l}\text { (3) Acuity Brands Winona }{ }^{\circledR} \\
\text { custom amber LED marker } \\
\text { lights }\end{array}$ & 4 & 4.5 & 5 & $\mathrm{n} / \mathrm{a}$ & $\mathrm{n} / \mathrm{a}$ & $\mathrm{n} / \mathrm{a}$ & $\mathrm{n} / \mathrm{a}$ & $\mathrm{n} / \mathrm{a}$ & $\mathrm{n} / \mathrm{a}$ & $\mathrm{n} / \mathrm{a}$ & $\mathrm{n} / \mathrm{a}$ & $\mathrm{n} / \mathrm{a}$ & $\mathrm{n} / \mathrm{a}$ & 2050 \\
\hline
\end{tabular}




\begin{tabular}{|c|c|c|c|c|c|c|c|c|c|c|c|c|c|c|c|}
\hline \multirow[b]{2}{*}{ Space } & \multirow[b]{2}{*}{ Luminaire Types } & \multicolumn{3}{|c|}{$\begin{array}{c}\text { Horizontal } \\
\text { illuminances in lux } \\
\text { at 30" work plane } \\
\text { u.o.n. }\end{array}$} & \multicolumn{3}{|c|}{$\begin{array}{l}\text { Vertical Illuminances } \\
\text { in lux on walls at } 5 \\
\text { above floor }\end{array}$} & \multicolumn{3}{|c|}{$\begin{array}{l}\text { Vertical illuminance } \\
\text { in lux on faces at } \\
\text { conf. table }\end{array}$} & \multicolumn{3}{|c|}{$\begin{array}{l}\text { Vertical illuminance } \\
\text { in lux on computer } \\
\text { screens, 4' aff }\end{array}$} & \multicolumn{2}{|c|}{$\begin{array}{l}\text { Luminaire luminance } \\
\left(\mathrm{cd} / \mathrm{m}^{2}\right)\end{array}$} \\
\hline & & Min & Avg & Max & Min & Avg & $\operatorname{Max}$ & Min & Avg & $\operatorname{Max}$ & Min & Avg & $\operatorname{Max}$ & Nadir & $45^{\circ}$ \\
\hline $\begin{array}{l}\text { Lounge area next to } \\
\text { atrium** }\end{array}$ & $\begin{array}{l}\text { (5) Visa Lighting PetalTM } \\
\text { 3-panel downward pendants, } \\
\text { hanging 32" above high-top } \\
\text { table }\end{array}$ & 197 & 234 & 271 & $\mathrm{n} / \mathrm{a}$ & $\mathrm{n} / \mathrm{a}$ & $\mathrm{n} / \mathrm{a}$ & & 196 & & $\mathrm{n} / \mathrm{a}$ & $\mathrm{n} / \mathrm{a}$ & $\mathrm{n} / \mathrm{a}$ & 8162 & 8989 \\
\hline Entry corridor*** & $\begin{array}{l}\text { (4) Visa Lighting Petal } \\
\text { 3-panel downward pendants }\end{array}$ & 90 & 95 & 101 & 64 & 75 & 91 & $\mathrm{n} / \mathrm{a}$ & $\mathrm{n} / \mathrm{a}$ & $\mathrm{n} / \mathrm{a}$ & $\mathrm{n} / \mathrm{a}$ & $\mathrm{n} / \mathrm{a}$ & $\mathrm{n} / \mathrm{a}$ & 8162 & 8989 \\
\hline \multicolumn{16}{|c|}{$\begin{array}{l}\text { * Illuminances were measured at dimming setting found in use, about } 1 / 3 \text { of maximum. Measured values were prorated by } 2.99 \text { to reflect the maximum output shown in this table. } \\
\text { ** Illuminance at center and edge of } 32 " \text { diameter, } 42 " \text { tall high-top table under pendant. } \\
\text { *** Horizontal illuminances measured at floor. } \\
\text { u.o.n = unless otherwise noted. }\end{array}$} \\
\hline
\end{tabular}




\subsection{OLED panel characteristics}

Four kinds of OLED panels are used in luminaires in these offices: the OLEDWorks Lumiblade Brite 1, Brite 2, Brite Amber, and the Keuka Module (a variant on the Brite 1 panel that features an integral driver). The Brite 2 panel is newly available, with higher color rendering ability and 50\% higher efficacy than the previous Brite 1 panel and Keuka Module. All products used the Brite 1 panels except for the Acuity Brands Winona ${ }^{\circledR}$ Trilia ${ }^{\mathrm{TM}}$ luminaires (Brite 2), the marker lights in the Zen/Mothers room (Brite Amber), and the task lights (Keuka Module). These panel characteristics are listed in Table 2.

Table 2. OLED panel characteristics, derived from OLEDWorks and luminaire manufacturer data sheets. L70 life values are those reported by the manufacturer, since there is no established Illuminating Engineering Society (IES) testing procedure for estimating OLED life. Values marked with an asterisk $(*)$ were derived from CALiPER testing for OLEDs.

\begin{tabular}{|c|c|c|c|c|c|c|c|c|c|c|c|}
\hline & Size & $\begin{array}{l}\text { CCT } \\
(\mathrm{K})\end{array}$ & $\begin{array}{l}\text { CRI } \\
\left(R_{\mathrm{a}}\right)\end{array}$ & $\begin{array}{c}\text { TM-30- } \\
2015 \\
\text { metrics } \\
R_{\mathrm{f}}, R_{\mathrm{g}}, \\
R_{\mathrm{CS}, \mathrm{h} 1}\end{array}$ & Lumens & $\begin{array}{l}\text { Current } \\
\text { (A) }\end{array}$ & $\begin{array}{c}\text { Lumi- } \\
\text { nance } \\
\left(\mathrm{cd} / \mathrm{m}^{2}\right)\end{array}$ & $\begin{array}{c}\text { Power } \\
\text { at } \\
\text { 24VDC } \\
\text { input } \\
\text { (W) }\end{array}$ & $\begin{array}{c}\text { Efficacy } \\
\text { at } \\
\text { 24VDC } \\
\text { input } \\
(\mathrm{lm} / \mathrm{W})\end{array}$ & $\begin{array}{c}\text { Approx } \\
\text { luminaire } \\
\text { efficacy } \\
\text { at } 120 \mathrm{~V} \\
\text { input } \\
(\mathrm{lm} / \mathrm{W})\end{array}$ & $\begin{array}{c}\text { Approx } \\
\mathrm{L}_{70} \\
\text { lifetime } \\
(\mathrm{hr})\end{array}$ \\
\hline Brite 1 & $\begin{array}{l}120.5 \mathrm{~mm} \\
\text { square }\end{array}$ & 2900 & $79 *$ & $\begin{array}{c}78 * \\
95 * \\
-13 \% *\end{array}$ & 300 & 0.368 & 8300 & 7.4 & 42 & 33.6 & 10,000 \\
\hline $\begin{array}{l}\text { Brite } 2 \\
\text { at max } \\
\text { current }\end{array}$ & $\begin{array}{c}120.5 \mathrm{~mm} \\
\text { square }\end{array}$ & 3000 & $\begin{array}{c}>90 \\
\left(R_{9}>70\right)\end{array}$ & $\begin{array}{c}86,100 \\
-3 \%\end{array}$ & 300 & 0.26 & 8300 & 5.3 & 57 & 45.6 & 10,000 \\
\hline $\begin{array}{l}\text { Brite } 2 \\
\text { at } \\
\text { current } \\
\text { used in } \\
\text { Trilia }\end{array}$ & $\begin{array}{c}120.5 \mathrm{~mm} \\
\text { square }\end{array}$ & 3000 & $\begin{array}{c}>90 \\
\left(R_{9}>70\right)\end{array}$ & $\begin{array}{c}86,100 \\
-3 \%\end{array}$ & 200 & $\sim 0.17$ & $\sim 5480$ & $\sim 3.4$ & $\mathrm{n} / \mathrm{a}$ & $\sim 56.7$ & 22,000 \\
\hline $\begin{array}{l}\text { Brite } \\
\text { Amber }\end{array}$ & $\begin{array}{l}41.5 \mathrm{~mm} \mathrm{x} \\
101.6 \mathrm{~mm}\end{array}$ & 1867 & $\mathrm{n} / \mathrm{a}$ & $\mathrm{n} / \mathrm{a}$ & 15 & 0.044 & 2000 & 0.27 & $\begin{array}{c}50 \\
\mathrm{~lm} / \mathrm{W} \text { at } \\
6.1 \\
\mathrm{VDC}\end{array}$ & 40 & 25,000 \\
\hline $\begin{array}{l}\text { Keuka } \\
\text { (Brite } \\
\text { 1) }\end{array}$ & $\begin{array}{c}69 \mathrm{~mm} \mathrm{x} \\
261.5 \mathrm{~mm}\end{array}$ & 2900 & $\begin{array}{c}80 \\
\left(R_{9}>0\right)\end{array}$ & $\mathrm{n} / \mathrm{a}$ & 300 & $\mathrm{n} / \mathrm{a}$ & 8300 & $\mathrm{n} / \mathrm{a}$ & 40 & 37.5 & 10,000 \\
\hline
\end{tabular}

Note that the OLED efficacies listed are based on new panels. As OLED panels age, the delivered voltage to the panel is expected to increase. In the case of the OLEDWorks Brite 2 panels, the increase is about $1.5 \mathrm{~V}$ from a starting point of $20 \mathrm{~V}$, or approximately $7.5 \%$, thus the power draw in watts at the end of their $\mathrm{L} 70$ life is also expected to be up to $7.5 \%$ higher.

A rise in voltage due to aging is not unique to OLED panels. Some LED packages are also known to exhibit such behavior, but it is believed to be smaller and more consistent across similar products due to the maturity of LED manufacturing. OLEDs, on the other hand, may have voltage rise characteristics that range from a few percent over the life of the product, as observed in OLEDWorks Brite 2 panels, to as much as $25 \%$ or more, as had been noted in the previous generation of OLEDWorks panels. A product 
design using either OLEDs or LEDs should be aware of the driving requirements of the light emitting component throughout its lifetime to ensure an adequate voltage range is available to deliver a constant current. Failure to account for the potential voltage rise may result in a driver's inability to deliver a constant current once the maximum voltage output of the driver has been reached. Consequently, the current would start to decline and result in light losses due to both a reduced current level and the natural efficacy loss of the panel.

\subsection{Color characteristics}

The LED products in the TeamDKB offices were specified at a nominal $3500 \mathrm{~K}$ CCT, with the OLED products specified at a nominal $3000 \mathrm{~K}$. Measurements of color characteristics using a UPRTek M250 meter (new, but uncalibrated) are shown in Table 3.

Table 3. Color characteristics of luminaires installed at DKB offices.

\begin{tabular}{|c|c|c|}
\hline Area/luminaire type & $\begin{array}{c}\mathrm{CCT} \\
(\mathrm{K})\end{array}$ & $\begin{array}{l}\text { CRI } \\
\left(R_{\mathrm{a}}\right)\end{array}$ \\
\hline Open office Acuity Mark LED Slot2 linear runs & 3476 & 82 \\
\hline Lounge Visa Petal ${ }^{\mathrm{TM}}$ OLED pendant & 2945 & 79 \\
\hline Copy room Designplan Blade OLED pendant & 2914 & 80 \\
\hline Private office Acuity Gotham EVO® LED downlight & 3472 & 83 \\
\hline Small conference room Acuity Winona ${ }^{\circledR}$ Trilia ${ }^{\mathrm{TM}}$ OLED pendant & 3074 & 91 \\
\hline Small conference room Birot Zhen OLED pendant & 2924 & 81 \\
\hline Reception desk OMLED One s5 OLED pendant & 2917 & 80 \\
\hline Break room Visa Limit ${ }^{\mathrm{TM}}$ OLED pendant & 2948 & 82 \\
\hline Zen/Mother’s room Acuity Winona ${ }^{\circledR}$ amber OLED nightlight & 2100 & 88 \\
\hline Private office OLED Devices OLED task light & 2911 & 82 \\
\hline
\end{tabular}

The difference in specified CCT for OLED and LED products was intentional. The surrounding LED lighting is $3500 \mathrm{~K}$ and the warmer $3000 \mathrm{~K}$ OLED products were designed to stand out with a slightly different quality, similar to using $3000 \mathrm{~K}$ halogen products for accent lighting inside an office space using $3500 \mathrm{~K}$ for general lighting.

The Brite 1 panels used in most of the luminaires exhibit a spectral power distribution (SPD) and color characteristics described in the following graphics and calculated from the IES TM-30-2015 tool. The color distortion icons in Figure 19 show a desaturation of reds and green object colors, suggesting that these colors may not appear as vivid compared to the reference source at $2900 \mathrm{~K}$. Contrast that result with the color analysis of the Brite 2 panels in Figure 20, where the Fidelity Index is higher (86), and the color icons show very little desaturation in any colors. 


\begin{tabular}{|c|c|}
\hline $\begin{array}{l}B_{1} \\
F\end{array}$ & $\begin{array}{l}79 \\
95\end{array}$ \\
\hline $\mathrm{CCT}(\mathrm{K})$ & 2919 \\
\hline $\mathrm{D}_{\mathrm{us}}$ & -0.0009 \\
\hline$x$ & \\
\hline$y^{\prime}$ & 0.4032 \\
\hline $\mathrm{CIE} F$ & 79 \\
\hline
\end{tabular}
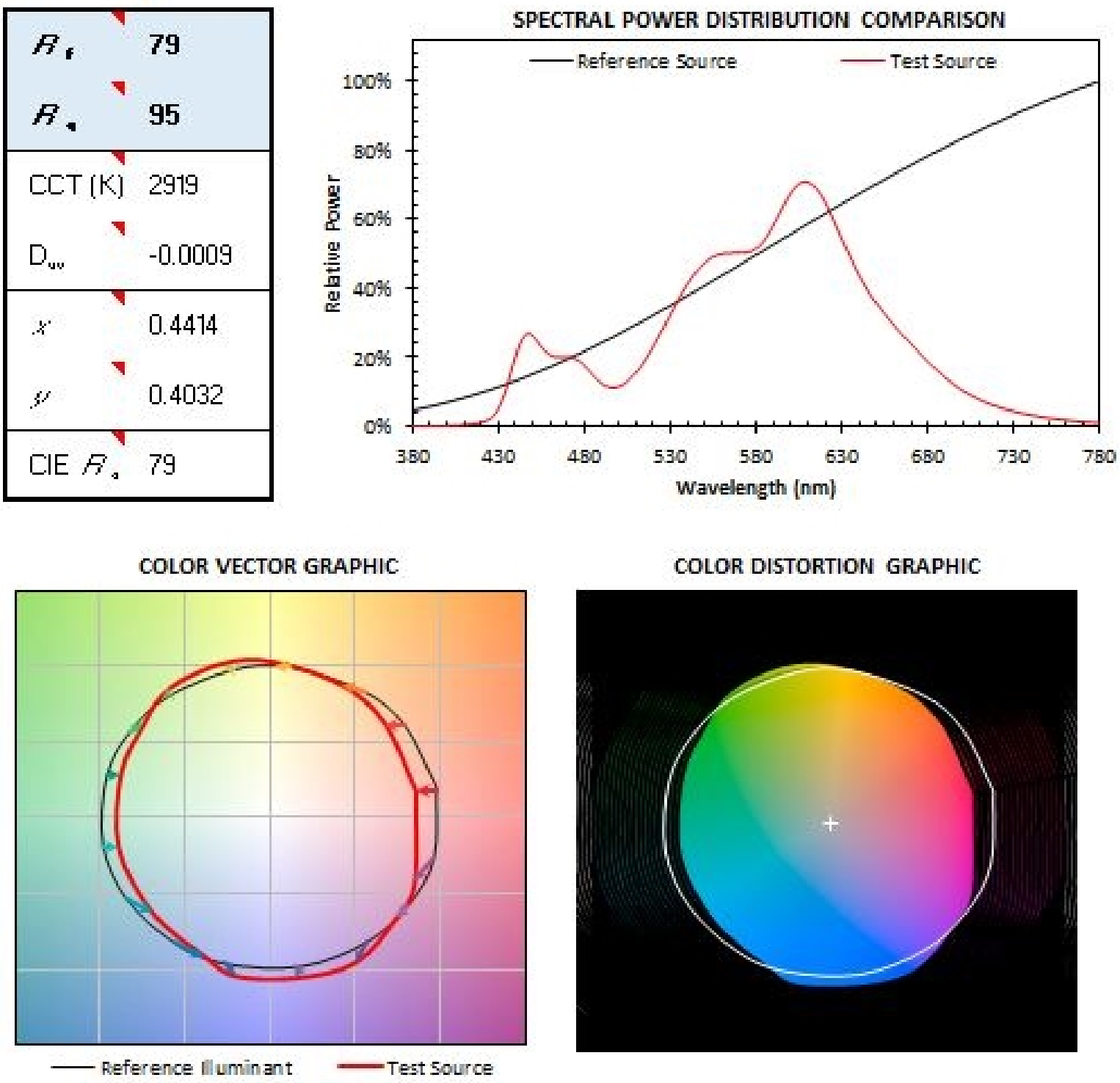

Figure 19. OLEDWorks Brite 1, $3000 \mathrm{~K}$ panel SPD and color characteristics as calculated using the IES TM-30-2015 Advanced Calculation Tool V1.97. This is based on CALiPER independent testing of the Visa Lighting Limit ${ }^{\mathrm{TM}}$ pendant luminaire. 


\begin{tabular}{|ll|}
\hline $\boldsymbol{R}_{\mathrm{f}}$ & $\mathbf{8 6}$ \\
$\boldsymbol{R}_{\mathrm{g}}$ & $\mathbf{1 0 0}$ \\
\hline $\mathrm{CCT}(\mathrm{K})$ & 3006 \\
$\mathrm{D}_{\mathrm{uv}}$ & -0.0017 \\
\hline$x$ & 0.4340 \\
\hline$y$ & $\checkmark$ \\
\hline $\mathrm{CIE} R_{\mathrm{a}}$ & 93 \\
\hline
\end{tabular}

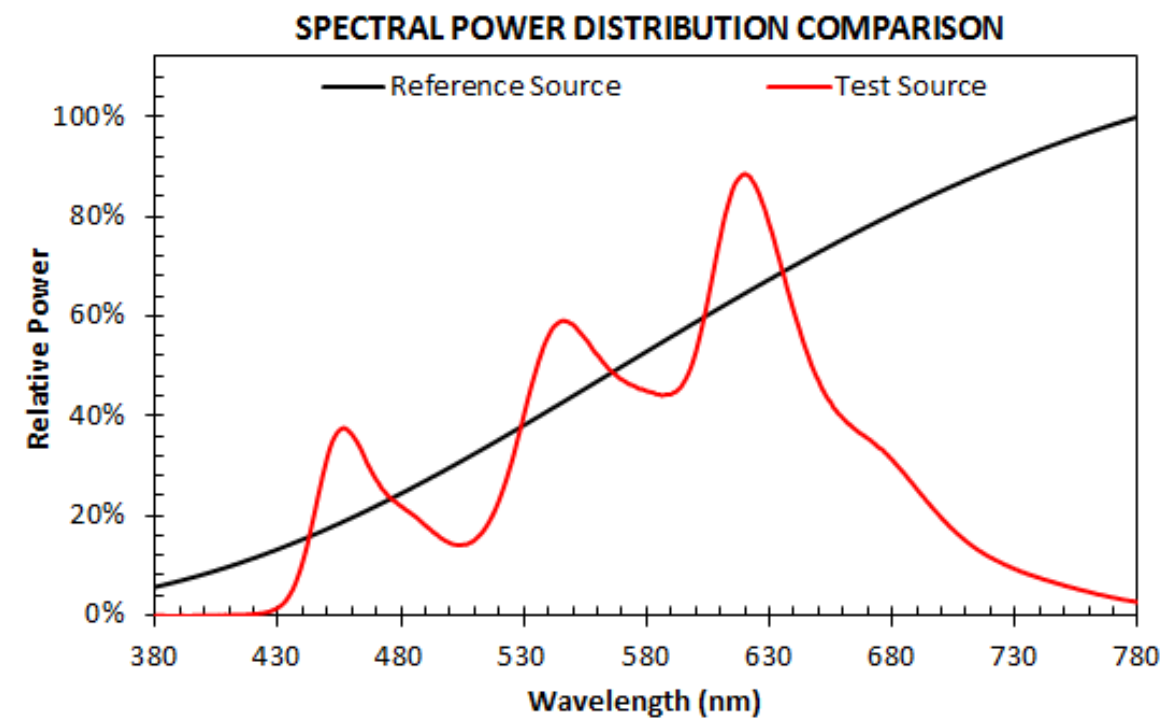

\section{COLOR VECTOR GRAPHIC}

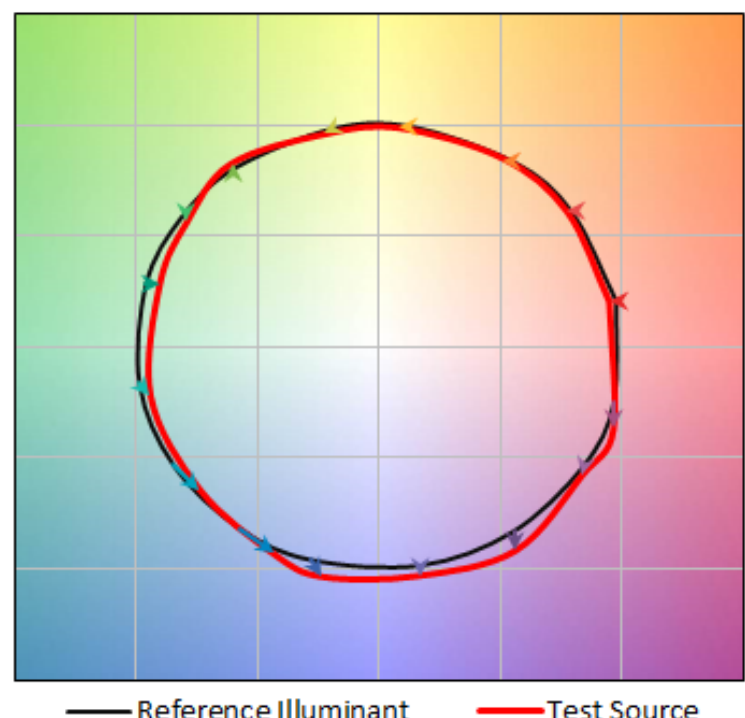

- Reference Illuminant
COLOR DISTORTION GRAPHIC

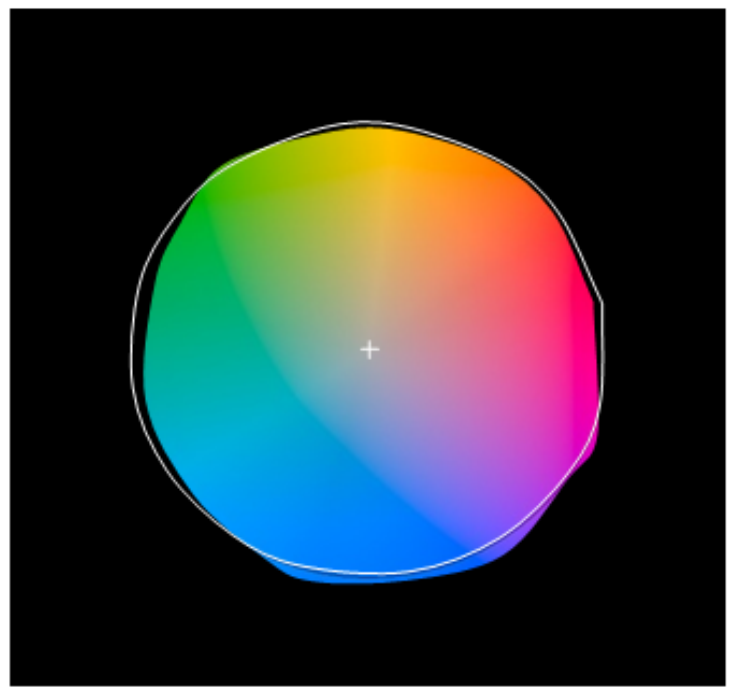

Figure 20. OLEDWorks Brite 2, $3000 \mathrm{~K}$ panel SPD and color characteristics as calculated using the IES TM-30-2015 Advanced Calculation Tool v1.97. Data source: OLEDWorks LLC.

\subsection{Controls}

The controls for the TeamDKB office were designed by Point Source Group in Rochester, NY, with input from the client. The goal was to maximize energy savings while keeping the cost of the controls manageable. Dimmers were used whenever possible and practical, using a 0-10V dimming protocol, which worked both with selected LED and OLED drivers, as well as with the Acuity Brands nLight ${ }^{\circledR}$ system that communicates control signals over CAT5 cabling through dimming power packs. A list of controls for typical areas follows: 
- Small offices, small conference rooms, and most smaller rooms. A wall-switch occupancy sensor with passive infrared technology, automatic off, and raise/lower dimming.

- Technical rooms, copy area, and employee entry/coat room. A wall-switch occupancy sensor with basic on/off control.

- Entry area, break room. One basic on/off/dim controller for each group of luminaire types within the room. Manual control only.

- Large conference room. A single manual-on control station with two on/off/dim controls, one for the Acuity Brands Winona ${ }^{\circledR}$ Trilia ${ }^{\mathrm{TM}}$ configurations, another for the Birot Zhen pendants. A ceiling mounted occupancy sensor tied into the $n$ Light $^{\circledR}$ system turns lights off when the room is unoccupied.

- Open office areas. Ceiling-mounted photosensors dim down LED linear lighting within 15 feet of the windows. Other luminaires in the open office are on on/off control wall switch control only.

\subsection{Temporal lighting artifacts (aka "flicker")}

Because LEDs and OLEDs have no inherent luminous persistence, in-situ temporal lighting artifact (TLA) measurements were taken of all office luminaire types. Care was taken to measure each luminaire's output while minimizing any contributions from daylight or ambient light from nearby luminaires. A UPRtek M250 flicker meter was used, new from the factory, but with no traceable calibration. Results are shown in Table 4. Flicker frequency readings of 0 indicate the waveform exhibited no detectable amplitude variation, or that the frequency exceeded the maximum range of the instrument (somewhere above $2000 \mathrm{~Hz}$ ). The meter lists three TLA measures: Flicker Index and Percent Flicker, which should be evaluated in conjunction with modulation frequency; and the Stroboscopic Visibility Measure (SVM). SVM is a metric proposed for use by the International Lighting Commission (CIE) and in the US by the National Electrical Manufacturers Association (NEMA), where a value of 1 indicates the threshold of visibility and values less than 1 are less visible to an average (i.e., not highly sensitive) observer. Values greater than 1 are more visible. Specific criteria for SVM values for different applications have yet to be defined.

The IES defines both the Flicker Index and Percent Flicker metrics, but makes no recommendation on target values for application.

IEEE Standard P1789-2015 set a standard for minimizing risk of health-related responses to flicker and stroboscopic effect ${ }^{1}$. Using a sliding scale, it sets a maximum Percent Flicker depending on the modulation frequency. For minimal risk, the IEEE standard recommends a rounded Percent Flicker value no higher than 0.08 times the modulation frequency. Those luminaires meeting that recommendation are marked in green in Table 4; those not meeting it are marked in pale red.

Only one of the LED luminaires exhibited a stroboscopic effect higher than recommended by the IEEE. That pendant downlight produced noticeable stroboscopic effects, with a measured frequency of $120 \mathrm{~Hz}, 48 \%$ flicker, Flicker Index of 0.147 at full output.

\footnotetext{
${ }^{1}$ Direct perception of flicker is one category of TLA, the perception of visual unsteadiness induced by a light stimulus which fluctuates with time, for a static observer in a static environment. The stroboscopic effect is another, the change in motion perception induced by a light stimulus fluctuating with time, for a static observer in a non-static environment. [Definitions adapted from CIE TN 006:2016]
} 
Similarly, all but the OMLED OLED luminaire produced consistently low levels of TLA, in both full and minimum output settings. Notably, many of the OLED drivers shifted the frequency to $1000 \mathrm{~Hz}$ or higher when dimmed to their lowest setting, making any increased modulation far less detectable. The OMLED luminaire was measured at full output at $665 \mathrm{~Hz}, 91 \%$ flicker, Flicker Index of 0.123. 
Table 4. Temporal Lighting Artifacts (aka flicker) characteristics of DKB space luminaires

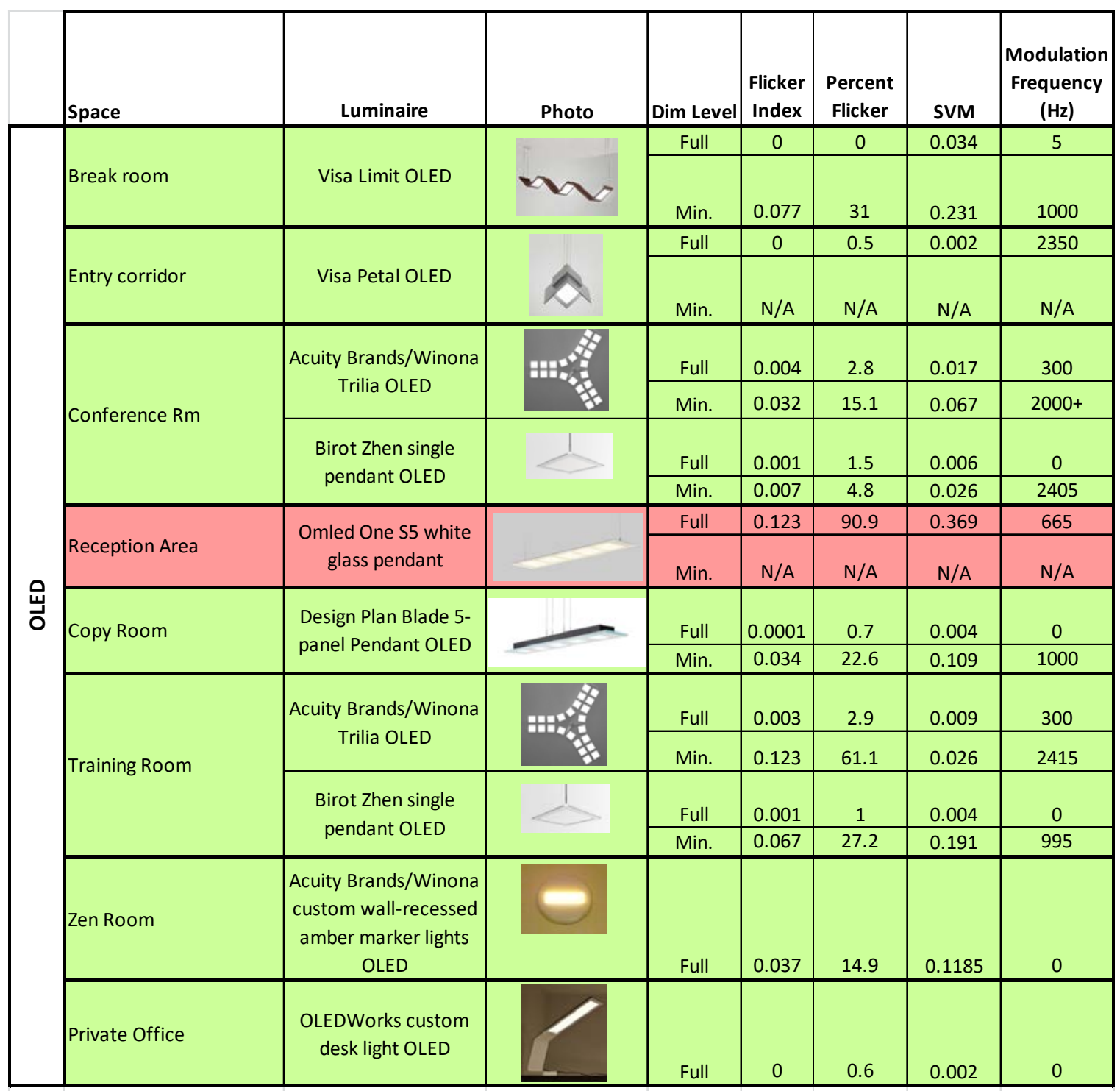

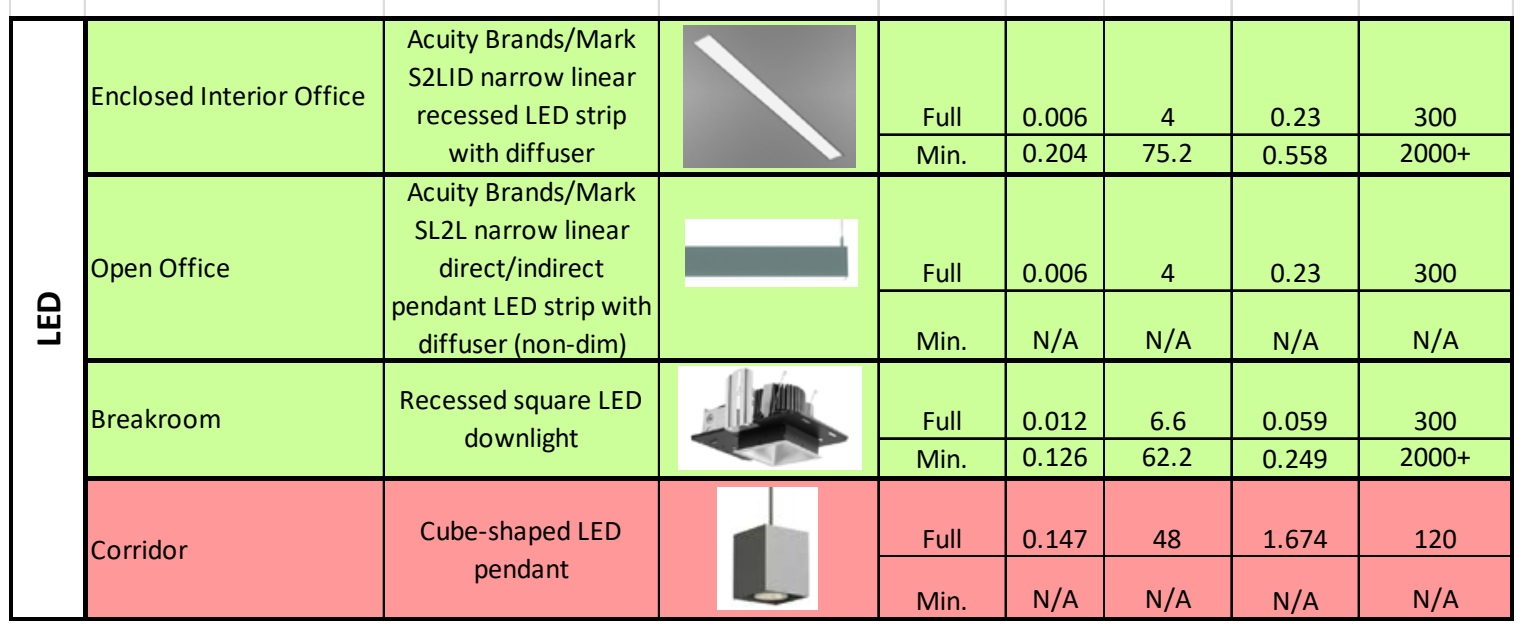




\subsection{Lighting power density}

PNNL calculated the lighting power density for the TeamDKB offices (Appendix A). The combination of LED and OLED lighting systems came to a total connected load of $0.6 \mathrm{~W} / \mathrm{ft}^{2}$. The current New York State energy code reference of ASHRAE/IES 90.1-2013, Building Area Method for Compliance, allows a baseline of $0.82 \mathrm{~W} / \mathrm{ft}^{2}$ for lighting office spaces. Of course, the total connected load doesn't represent actual lighting power at any point in time. Actual lighting energy use is expected to be lower due to automatic vacancy controls that shut off lighting when spaces are unoccupied, photosensor dimming that reduces the output of the linear LED luminaires near windows in response to available daylight, and manual dimming.

\subsection{Reaction from office occupants}

PNNL interviewed four staff members selected by the office manager to represent a range of ages, levels in the firm, workspace type, and proximity to windows. They were interviewed before and after the move to the new office spaces. Each was located in different areas of the DKB space, both before the move and afterward. The interviews were conversational, but included a consistent set of questions (Appendix B). These individuals were asked about their experience with the spaces, lighting, and controls; and were also reassured that their responses would be kept confidential and reported anonymously. Their feedback regarding the new office space was positive, especially given the contrast to their previous rabbit-warren office layouts with dated, fixed-output, deep-cell parabolic louver, fluorescent luminaires. They appreciate the soft, comfortable appearance of the OLED lighting, and enjoy showing a new kind of SSL to visiting friends and colleagues, and those that have explored the dimming options appreciate that flexibility. They also like the LED luminaires, although some find them excessively bright to view.

OLED panels produce a soft, almost spherical, light pattern, called a cosine distribution. ${ }^{1}$ The cosine distribution (Figure 21) gives the panel the same luminance from all viewing angles up to $90^{\circ}$. That luminance could result in the perception of glare, especially when viewed from angles of $60^{\circ}$ to $90^{\circ}$ from the luminaire's nadir in panels emitting between 200 and 300 lumens, as the OLEDWorks panels do. However, in this installation none of the office occupants reported glare issues. It is likely that in spreading the emitted light evenly across the $100 \mathrm{~mm}$ by $100 \mathrm{~mm}$ panel emitting surface, the luminance of roughly 5500 to $8300 \mathrm{~cd} / \mathrm{m}^{2}$ is tolerable for an eye adapted to interior office light levels. ${ }^{2}$

The soft distribution of light from the OLED panels also produces relatively high vertical illuminances on walls and faces in a space, and reduces the sharpness of projected shadows from objects, much like the effect from indirect lighting.

\footnotetext{
${ }^{1}$ A cosine distribution is one where the intensity at $5^{\circ}$ from nadir is the nadir intensity multiplied by the cosine of $5^{\circ}$, the intensity at $10^{\circ}$ from nadir is the nadir intensity multiplied by the cosine of $10^{\circ}$, etc. This appears as a circle on a polar plot, drawn from the origin. By definition, the luminance of the evenly lit surface at any viewing angle below $90^{\circ}$ is identical, and only small variations from this value are expected from field measurements.

${ }^{2}$ For reference, luminances of 6000 to $8000 \mathrm{~cd} / \mathrm{m} 2$ roughly correspond to the luminance of a bare T12 fluorescent lamp; 8000 - 11,000 cd/m2 for a T8 fluorescent lamp; and 16,000 - 35,000 cd/m2 for a T5 fluorescent lamp, depending on output level and ballast factor.
} 


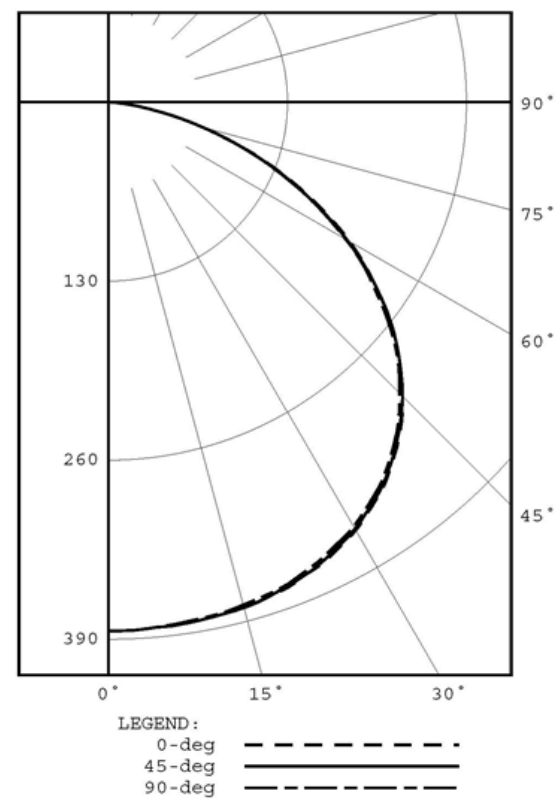

Figure 21. Polar plot of the photometric distribution from the Designplan Blade ${ }^{\mathrm{TM}}$ OLED luminaire, showing a near-cosine distribution. (Source: CALiPER test 16-F18A, ITL88543.)

One endorsement for the new LED and OLED lighting system is that few employees even think about lighting in the new offices. The greatest lighting complaint from the interviewees with a clear view of southwest-facing windows was occasional glare from the setting sun. (They have learned to use window shades as the remedy.) One person commented on glare from the LED cube pendants near the reception desk. Two of the interviewed individuals mentioned that there are two people in the office who get migraines from lighting glare or flicker and were bothered by fluorescent lamps exhibiting end-of-life instability in the older offices, but are pleased with the comfort of the specific OLED luminaires installed.

No one commented on computer screen reflections from either the OLED or the LED luminaires. Light levels seemed appropriate for tasks performed in all office spaces; staff reported that they almost never use the dimming systems for raising and lowering light levels, but instead use the lighting at full output or whatever setting the previous occupant used. Two of the four appreciate the portable task lights, especially for reading printed financial reports. One is an employee in an interior office who keeps the task light on continuously in the darker desk area near the computer screens; the other occupies a perimeter office facing west, and appreciates the ease in reading that additional light offers. One individual who works far from the windows feels the need for a supplementary task light around the desk.

No flicker or color problems were reported. Training rooms in the previous TeamDKB offices had clumsy controls that offered on/off control only, and when used to control projection screen reflections, threw the presenter into gloom and lulled the darkened audience to sleep. Now training and conference rooms have dimming control, and that allows a uniform note-taking light that also illuminates the presenter's face without interfering with presentation screen visibility.

The appearance of the OLED luminaires wins high praise from employees. Several commented that friends and family wanted to install the Visa Petal ${ }^{\mathrm{TM}}$ pendants in their own homes because they are residential scale, and "neat-looking." 


\subsection{Costs}

OLEDWorks LLC received support from the New York Energy Research and Development Authority (NYSERDA) to help purchase the OLED luminaires installed at the TeamDKB offices. This subsidy was in support of NYSERDA's energy efficiency and economic development mission. The actual luminaire pricing was not available to DOE.

According to David DeJoy, Managing Partner at TeamDKB, the installation labor cost was no more for the OLED luminaires than for the LED luminaires. Because the ceilings were either open and easily accessed, or constructed using T-bar acoustical ceiling systems, there was no additional complexity in wiring or controls that prompted the electrical contractor to increase costs.

\subsection{Unexpected Test of Robustness}

TeamDKB's new offices are located in the Tower280 at Midtown building in Downtown Rochester N.Y. In the early hours of a Sunday in March 2017, a fire occurred in part of the underground system that blew a cover off a manhole at the corner of Broad and Chestnut Streets. The damage in the underground area was described by the electric utility as "catastrophic" and resulted in a loss of power in the entire Tower 280 building except for certain emergency systems. The TeamDKB office was without power until about 11:30 p.m. that evening, when only one of the three phases of power was restored. The result of the partial restoration was that many of the OLED and LED lights began flashing. These lights were manually shut down until full power was restored the next morning.

Not a single light fixture failed under these conditions. All of the OLEDs, LEDs, and drivers survived and were still working as of the date of this writing. This was an unexpected "test" of the robustness of all of the luminaires and they all passed.

\subsection{Conclusions}

The TeamDKB offices are unique in that there were eight different OLED architectural lighting products installed and in daily use throughout, plus a hybrid OLED and LED product added since the PNNL site visit, as noted below.

\subsection{Summary}

TeamDKB strove to create spaces that were visually distinctive and energy efficient, equipped with products designed to enable comfortable seeing for performing visual tasks, and which projected a contemporary attitude toward work style and progressive ideas.

- The lighting system expresses creativity and innovation, making a statement to TeamDKB's clients and staff.

- The OLED luminaires use $3000 \mathrm{~K}$ panels (except for the amber OLED panels used in the Zen/Mother's room), which are warmer than the $3500 \mathrm{~K}$ LED downlights and linear products. Yet, there is no visually jarring difference in appearance. The color quality of the OLED panels ranges 
from very good (Brite 1 panels) to excellent (Brite 2 panels), with CRI values ranging from 79 to 91, $\mathrm{R}_{9}$ of 29 to $70 ; R_{f}$ of 79 to $86, R_{g}$ of 95 to 100 , and chroma shift $R_{\mathrm{cs}, \mathrm{h} 1}$ of $-13 \%$ to $4 \%$, respectively.

- The OLED panels exhibit surface luminances as high as $9300 \mathrm{~cd} / \mathrm{m}^{2}$ (in the Visa Lighting Petal ${ }^{\mathrm{TM}}$ pendants in the lounge area), yet none of the staff interviewed found them excessively bright. In comparison, some of the staff found the linear LED lighting to be glaring to view, with luminances measuring from 12,000 to $28,000 \mathrm{~cd} / \mathrm{m}^{2}$.

- The OLED panels were almost all driven by dedicated OLED drivers, and two of the luminaire types (OMLED One s5 and the OLED Devices task light with Keuka Module) incorporated OLED panels with integral drivers, eliminating the bulk of a remote driver.

- The OLED luminaires are dimmable in almost all areas, and exhibit virtually no temporal light artifacts (aka, flicker) that would exceed the guidelines of the IEEE Standard P1789-2015 in either maximum or minimum output range of the dimmer.

- The exposed OLED panels deliver a soft, minimal-shadow lighting that makes faces and expressions visible, and increases room brightness by delivering light to vertical surfaces. At the panel luminances used, this is achieved without employees reporting glare.

- Lighting power density for the TeamDKB offices is $0.60 \mathrm{~W} / \mathrm{ft}^{2}$ for the total connected load. The actual lighting energy use is expected to be lower than implied by that lighting power density, due to automatic vacancy controls that shut off lighting when spaces are unoccupied, photosensor dimming that reduces the output of the linear LED luminaires near windows in response to available daylight, and manual dimming.

- Feedback from staff of TeamDKB indicates they find the lighting system functional and enjoyable.

- There have been no OLED panel or driver failures at TeamDKB, after 9 months of operation.

OLED products face challenges in the following respects:

- The efficacies of OLED panels are still well below those of LED products. The OLED luminaires on this project range between 20 and $60 \mathrm{~lm} / \mathrm{W}$, compared to the LED products at approximately 80 to 90 $\mathrm{lm} / \mathrm{W}$. However, projected performance for the next generation of OLED panels is $90 \mathrm{~lm} / \mathrm{W}$ at a nominal (low) brightness of $3000 \mathrm{~cd} / \mathrm{m}^{2}$, CRI of 90, lifetime $>50,000$ hours; Efficacy of $80 \mathrm{~lm} / \mathrm{W}$ at $8300 \mathrm{~cd} / \mathrm{m}^{2}$, CRI of 90 , lifetime of 30,000 hours.

- OLED panels draw more power as they age, so it is important for designers and engineers to provide "headroom" on the OLED loads in electrical circuits so that circuits will not be overloaded over time. To account for panel-to-panel variations when new, panel changes over time, and for variations in ambient temperature, lighting power density calculations are often recommended to include an additional $15 \%$ of power draw for OLED loads, although this GATEWAY report only calculated the installed watts based on installed (i.e., new) power values.OLED luminaires are typically sold at a premium price point that limits their wider use in projects and applications; luminaire pricing was not available to DOE for this project. 


\subsection{Epilogue}

New OLED products have entered the market in 2017, prompting DKB to remove some of the LED linear products in the open office in March 2017, and replace them with a nominal 4-foot linear configuration of the Acuity Brands Peerless Olessence ${ }^{\mathrm{TM}}$ luminaire (Figure 22). This has a single line of 3500 K LEDs delivering uplight, and eight 3000 K OLEDWorks Brite 2 series 50 by 200 mm panels downward. This luminaire combines the high efficiency of the LEDs for indirect lighting with the comfort and appearance of the visible OLED panels on the downward side. The overall luminaire performance is rated at $71 \mathrm{~lm} / \mathrm{W}, 75 \mathrm{~lm} / \mathrm{W}$, or $81 \mathrm{~lm} / \mathrm{W}$ depending on the LED package specified; DOE has not tested this product or verified the ratings.

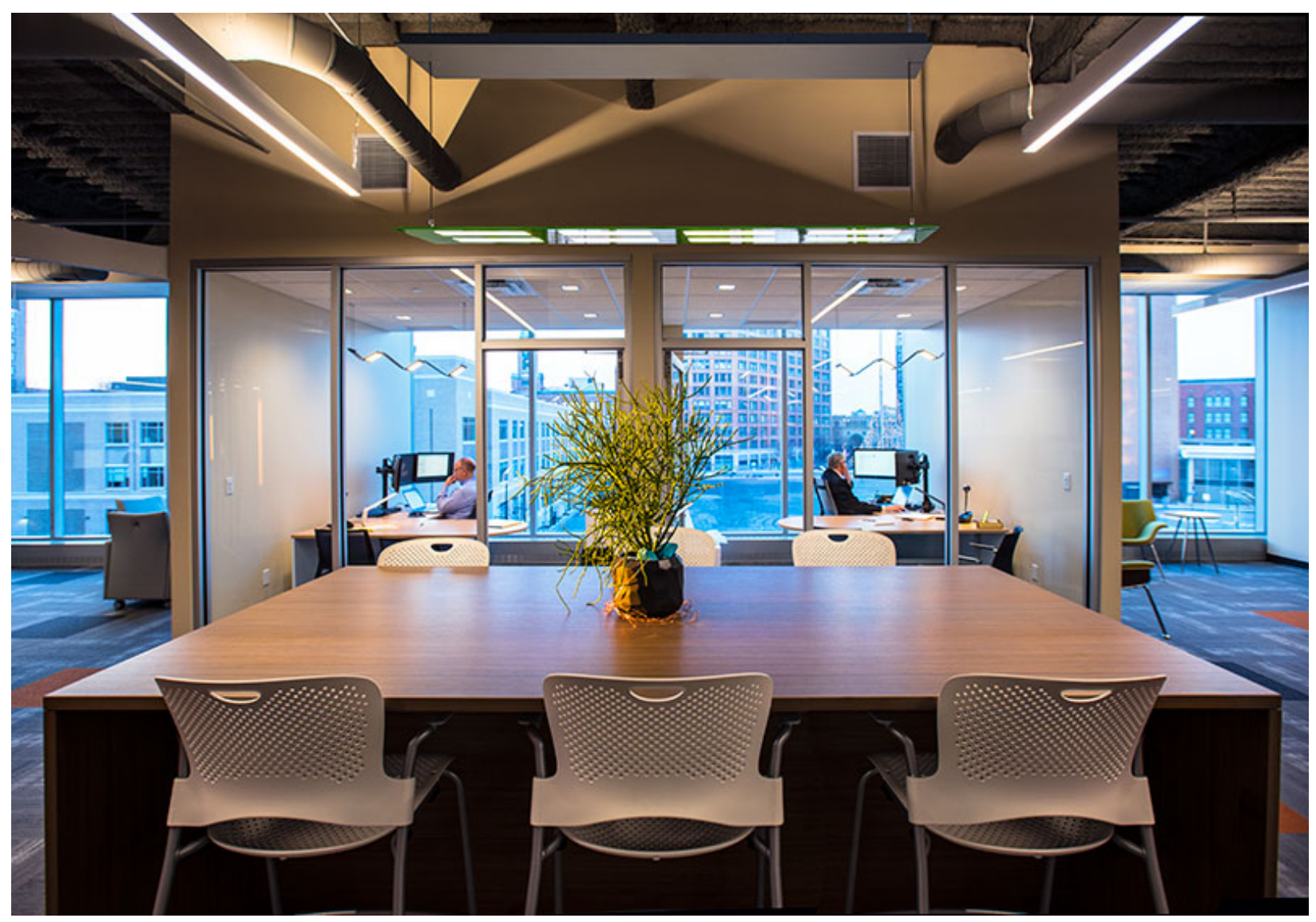

Figure 22. The newly installed Acuity Brands Peerless Olessence ${ }^{\mathrm{TM}}$ luminaire, mounted in place of linear LED luminaires in the open office area. Photo courtesy OLEDWorks LLC and DeJoy Knauf \& Blood, LLP. 


\section{Appendix A TeamDKB Offices Lighting Power Density Calculation, Total Connected Lighting Load}

\begin{tabular}{|c|c|c|c|c|c|c|c|c|c|c|c|c|c|c|c|}
\hline & $\begin{array}{c}\text { Acuity } \\
\text { Brands } \\
\text { Mark } \\
\text { Slot2 } \\
\text { LED } \\
\text { pendant } \\
\text { up/dn }\end{array}$ & $\begin{array}{c}\text { Acuity } \\
\text { Brands } \\
\text { Mark } \\
\text { Slot2 } \\
\text { LED } \\
\text { recessed }\end{array}$ & $\begin{array}{c}\text { V2 } \\
\text { Lighting } \\
4 " \\
\text { square } \\
\text { cube } \\
\text { LED } \\
\text { pendant }\end{array}$ & $\begin{array}{c}\text { Acuity } \\
\text { Brands } \\
\text { Gotham } \\
\text { EVO }^{\circledast} \\
\text { square } \\
\text { LED } \\
\text { downlt }\end{array}$ & $\begin{array}{c}\text { Acuity } \\
\text { Brands } \\
\text { Winona }^{\circledR} \\
\text { Trilia }^{\mathrm{TM}} \\
\text { TRI config. } \\
\text { w/ } \\
\text { OLEDWor } \\
\text { ks panels at } \\
200 \mathrm{~lm} \text { ea }\end{array}$ & $\begin{array}{c}\text { Acuity } \\
\text { Brands } \\
\text { Winona }^{\circledR} \\
\text { Trilia }^{\mathrm{TM}} \text { STR } \\
\text { config. w/ } \\
\text { OLEDWorks } \\
\text { panels at } \\
200 \mathrm{~lm} \text { ea } \\
\end{array}$ & $\begin{array}{c}\text { Visa } \\
\text { Lighting } \\
\text { OLED } \\
\text { Petal }{ }^{\mathrm{TM}} \\
\text { pendant } \\
(*) \\
\end{array}$ & $\begin{array}{c}\text { Visa } \\
\text { Lighting } \\
\text { OLED } \\
\text { Limit } \\
\text { pendant } \\
(*)\end{array}$ & $\begin{array}{c}\text { Designplan } \\
\text { Blade } \\
\text { OLED } \\
\text { pendant }\end{array}$ & $\begin{array}{c}\text { OMLED } \\
\text { OLED } \\
\text { One s5 } \\
\text { pendant } \\
\left({ }^{*}\right)\end{array}$ & $\begin{array}{c}\text { Birot } \\
\text { Zhen } \\
\text { OLED } \\
\text { pendant } \\
(*) \\
\end{array}$ & $\begin{array}{c}\text { Acuity } \\
\text { Brands } \\
\text { Lithonia } \\
\text { STL LED } \\
\text { strip }\end{array}$ & $\begin{array}{c}\text { Acuity } \\
\text { Brands } \\
\text { Lithonia } \\
\text { BLT LED } \\
\text { strip }\end{array}$ & $\begin{array}{c}\text { Acuity } \\
\text { Brands } \\
\text { Winona }^{\circledR} \\
\text { OLED } \\
\text { recessed } \\
\text { amber } \\
\text { marker } \\
\text { lights }(*)\end{array}$ & Total \\
\hline Fixture Counts & 71 & 32 & 8 & 85 & 7 & 1 & 10 & 15 & 2 & 3 & 4 & 7 & 4 & 5 & \\
\hline Fixture Tyре & A & A1 & B & B1 & $\mathrm{C}$ & D & E & $\mathrm{F}$ & G & $\mathrm{H}$ & I & $\mathrm{J}$ & K & $\mathrm{n} / \mathrm{a}$ & \\
\hline Power at $24 \mathrm{~V}$ & $\mathrm{n} / \mathrm{a}$ & $\mathrm{n} / \mathrm{a}$ & $\mathrm{n} / \mathrm{a}$ & $\mathrm{n} / \mathrm{a}$ & $\mathrm{n} / \mathrm{a}$ & $\mathrm{n} / \mathrm{a}$ & 27 & 27.7 & $\mathrm{n} / \mathrm{a}$ & 30 & 8.4 & $\mathrm{n} / \mathrm{a}$ & $\mathrm{n} / \mathrm{a}$ & 0.27 & \\
\hline $\begin{array}{l}\text { Transformer } \\
\text { Efficiency }\end{array}$ & $\mathrm{n} / \mathrm{a}$ & $\mathrm{n} / \mathrm{a}$ & $\mathrm{n} / \mathrm{a}$ & $\mathrm{n} / \mathrm{a}$ & $\mathrm{n} / \mathrm{a}$ & $\mathrm{n} / \mathrm{a}$ & 0.86 & 0.86 & $\mathrm{n} / \mathrm{a}$ & 0.86 & 0.80 & $\mathrm{n} / \mathrm{a}$ & $\mathrm{n} / \mathrm{a}$ & 0.80 & \\
\hline Watts & 51 & 44 & 18.7 & 12.8 & 81.4 & 27.1 & 31.4 & 32.2 & 54.1 & 34.9 & 10.5 & 45.2 & 29.9 & 0.34 & \\
\hline Total Watts & 3621 & 1408 & 149.6 & 1088 & 569.8 & 27.1 & 314.0 & 483.1 & 108.2 & 104.7 & 42.0 & 316.4 & 119.6 & 1.7 & 8353 \\
\hline $\begin{array}{l}\text { Project Area } \\
\left(\mathrm{ft}^{2}\right)\end{array}$ & & & & & & & & & & & & & & & 13,905 \\
\hline $\begin{array}{l}\text { Lighting Power } \\
\text { Density }\left(\mathrm{W} / \mathrm{ft}^{2}\right)\end{array}$ & & & & & & & & & & & & & & & 0.60 \\
\hline
\end{tabular}





\section{Appendix B PNNL Interview Questions for TeamDKB staff, Before and After Move to New Offices}

- What is your role in the firm? What are your daily visual tasks?

- Where do you work in the office?

- Describe your work space. Do you have a private office, workstation, or other?

- Do you have windows or a view? Do you use paper, electronic screens, do you confer with others in your office?

- Describe the lighting in your workspace. How is it controlled (i.e., with switches or dimmers on the wall, occupancy sensors, no controls at all)?

- Do you have any problems seeing your work materials? Any troubles seeing the computer screens or reference materials? Do you notice any reflected glare on computer screens, or uncomfortable glare from lighting or windows? Do you have comments on the color of light? Have you observed flicker from lighting?

- Do you use a task light, or would you like one to supplement your desk lighting?

- Are there any lighting-related issues in the rest of the spaces you use, such as conference rooms or lobbies? 